\title{
Lophogastrida and Mysida (Crustacea) of the "DIVA-1" deep-sea expedition to the Angola Basin (SE-Atlantic)
}

\author{
Karl J. WITTMANN \\ Department of Environmental Health, Medical University of Vienna, \\ Kinderspitalgasse 15, A-1090 Vienna, Austria. \\ Email: karl.wittmann@meduniwien.ac.at
}

urn:1sid:zoobank.org:author:C90E7BC4-A27A-4B41-93F3-6224D17795FF

\begin{abstract}
Three species of Lophogastrida and eight Mysida are documented for samples from 5161-5497 m bottom depth in the Angola Basin. Previously known latitudinal ranges are extended southward for five species, and bathymetric ranges extended beyond $5000 \mathrm{~m}$ for six species. Upon revision of the subfamily Petalophthalminae (Mysidae), four species previously attributed to the genus Petalophthalmus are integrated into Ipirophthalmus gen. nov. as I. liui gen. et comb. nov., I. caribbeanus gen. et comb. nov., I. oculatus gen. et comb. nov., and I. macrops gen. et comb. nov., mainly based on the structure of eyes and presence of setae on the telson. Petalophthalmus cristatus sp. nov. is described based on its reduced cornea and the structure of eyestalks, rostrum, mandibles, and telson. The structure of mouthparts, foregut and maxillipeds suggests an omnivorous mode of life. The diagnosis of the tribe Calyptommini (Mysidae: Erythropinae) is widened to cover the 3-segmented, uniramous fourth male pleopod and the non-incised eyeplate with horn-like rudiments of eyestalks in Abyssomysis cornuta gen. et sp. nov. The structure of mandibles, foregut, and second maxilliped suggest detritus feeding in this species. Keys to the Calyptommini and Petalophthalminae are given.
\end{abstract}

Keywords. Taxonomic revision, first description, biogeography, abyssal zone, equatorial East Atlantic.

Wittmann K.J. 2020. Lophogastrida and Mysida (Crustacea) of the "DIVA-1" deep-sea expedition to the Angola Basin (SE-Atlantic). European Journal of Taxonomy 628: 1-43. https://doi.org/10.5852/ejt.2020.628

\section{Introduction}

Previous knowledge of the Lophogastrida and Mysida in deep waters of the Angola Basin is based on meso- to bathypelagic samples taken by the "Valdivia" Expedition in Sep. 1898 at six stations, with vertical hauls towed from 600-4000 $\mathrm{m}$ depth up to the surface (station and sampling data available in Deutsche Tiefsee-Expedition 1899). Five species of Lophogastrida and seven species of Mysida were recorded (Illig 1930; Wittmann in press). Using updated synonymy, the "Valdivia" lophogastrids from the Angola Basin are Fagegnathophausia gracilis (Willemoës-Suhm, 1875), Neognathophausia gigas (Willemoës-Suhm, 1873), Eucopia grimaldii H. Nouvel, 1942, E. sculpticauda Faxon, 1893 and E. unguiculata (Willemoës-Suhm, 1875). The corresponding Mysida are Arachnomysis leuckartii Chun, 1887, A. megalops Zimmer, 1914, Boreomysis microps G.O. Sars, 1883, Caesaromysis hispida Ortmann, 1893, Echinomysis chuni Illig, 1905, Euchaetomera glyphidophthalmica Illig, 1906 and 
Euchaetomeropsis merolepis (Illig, 1908). The "Valdivia" material shares three lophogastrid species but no mysids with the below-reported yield of the "DIVA-1" Expedition. The great difference between the yields of these expeditions probably reflects both the different bathymetric distribution of the species and the use of different sampling gear.

The gears used by the "Valdivia" did not reach down to the oceanic abyssal plain of the Angola Basin. One century later this was achieved by the "DIVA-1" Expedition with RV "Meteor" during cruise M48 (Kröncke \& Türkay 2003). The first leg in July 2000 focused on compositional changes of the benthic organism assemblages along a transect of about $700 \mathrm{~km}$ from $22^{\circ} 21^{\prime} \mathrm{S}, 3^{\circ} 19^{\prime} \mathrm{E}$ to $16^{\circ} 25^{\prime} \mathrm{S}, 5^{\circ} 27^{\prime} \mathrm{E}$, depth range 5148-5500 m (Balzer et al. 2006). This transect is crossed by the Angola-Benguela Front of oceanic water masses (Kröncke \& Türkay 2003). Besides being designed to collect great numbers of invertebrates, special emphasis was placed on determining the diversity of peracarid crustaceans, with a preliminary list of taxa, including the Lophogastrida and Mysida, provided by Brandt et al. (2005). Ten out of 35 stations yielded lophogastrids and mysids (Table 1); in comparison, the other peracarid orders were represented by many more specimens and species. Nonetheless, this material revealed a wealth of biogeographical and taxonomical novelties, including revisions of the subfamily Petalophthalminae Czerniavsky, 1882 (fam. Petalophthalmidae Czerniavsky, 1882) and of the tribe Calyptommini W.M. Tattersall, 1909 (fam. Mysidae Haworth, 1825), with first descriptions of two genera and two species; and the ranges of seven other species were extended.

\section{Material and methods}

\section{Repositories}

SMF $=$ Senckenberg Museum, Frankfurt am Main, Germany

$\mathrm{ZMH}=$ Zoological Museum of Hamburg, Germany

\section{Abbreviations}

$\mathrm{BL}=$ body length

$\# \quad=$ station numbers in Table 1

\section{Material}

Not counting exuviae and fragments, 41 specimens of mysids and 14 lophogastrids were studied from benthic and pelagic samples taken in July 2000 by the "DIVA-1" deep-sea expedition with RV "Meteor" at ten stations in the Angola Basin (Table 1). Here not included are undeterminable fragments of four mysid specimens from station nos 320, 339 and 348. The materials are preserved in ethanol, unless explicitly stated as mounted in Swan medium on slides, and kept at SMF and ZMH. The expedition log, station data and most of the here treated sampling data are provided in Balzer et al. (2006). The nonclosing Agassiz Trawl with mesh size $10 \mathrm{~mm}$ is further detailed in Türkay et al. (2006). The self-closing epibenthic sledge was equipped with epinet and supranet, each with mesh-size $0.3 \mathrm{~mm}$, as detailed by Brandt et al. (2006). These nets were only partly specified on vial labels of the material examined.

\section{Laboratory methods}

Preparation, measurements and examination of materials as in Wittmann (2008). Body length measured according to Tattersall \& Tattersall (1951) from the anterior margin of the carapace to the posterior margin of the telson, excluding the spines. Antennae, eyes, carapace and pleonites measured along dorsal midline unless stated otherwise. As novelties the eyeplate was detached and expanded on slides in Abyssomysis cornuta gen. et sp. nov., eyes together with ocular symphysis on one slide in Petalophthalmus cristatus sp. nov. The statolith mineral was determined according to Wittmann et al. (1993). 
Table 1. Sampling data ${ }^{1}$ of the "METEOR" cruise 48 leg 1 to the Angola Basin, SE-Atlantic: Lophogastrida and Mysida.

\begin{tabular}{|c|c|c|c|c|c|c|}
\hline $\begin{array}{c}\text { Station } \\
\text { (aria) }\end{array}$ & $\begin{array}{c}\text { Start } \\
\text { coordinates }\end{array}$ & $\begin{array}{c}\text { End } \\
\text { coordinates }\end{array}$ & $\begin{array}{l}\text { Depth } \\
(\mathrm{m})\end{array}$ & UTC & Gear & $\begin{array}{c}\text { Species } \\
\text { recorded }^{2}\end{array}$ \\
\hline $\begin{array}{c}\# 318 \\
(1)\end{array}$ & $\begin{array}{l}22^{\circ} 19.978^{\prime} \mathrm{S} \\
3^{\circ} 18.342^{\prime} \mathrm{E}\end{array}$ & $\begin{array}{l}22^{\circ} 20.249^{\prime} \mathrm{S} \\
3^{\circ} 18.439^{\prime} \mathrm{E}\end{array}$ & $5179-5180$ & $\begin{array}{l}\text { 9 Jul. } 2000 \\
13: 25-14: 44\end{array}$ & $\begin{array}{l}\text { epibenthic } \\
\text { sledge }\end{array}$ & $\begin{array}{l}\text { Paramblyops rostratus } \\
\text { Parapseudomma calloplura }\end{array}$ \\
\hline $\begin{array}{l}\# 320 \\
(1)\end{array}$ & $\begin{array}{l}22^{\circ} 19.914^{\prime} \mathrm{S} \\
3^{\circ} 17.956^{\prime} \mathrm{E}\end{array}$ & $\begin{array}{c}22^{\circ} 20.049^{\prime} \mathrm{S} \\
3^{\circ} 17.957^{\prime} \mathrm{E}\end{array}$ & $5161-5162$ & $\begin{array}{l}\text { 10 Jul. } 2000 \\
11: 00-11: 28\end{array}$ & $\begin{array}{l}\text { epibenthic } \\
\text { sledge }\end{array}$ & $\begin{array}{l}\text { Amblyops tenuicauda } \\
\text { Parapseudomma calloplura }\end{array}$ \\
\hline $\begin{array}{c}\# 321 \\
(1)\end{array}$ & $\begin{array}{l}22^{\circ} 20.640^{\prime} \mathrm{S} \\
3^{\circ} 23.567^{\prime} \mathrm{E}\end{array}$ & $\begin{array}{l}22^{\circ} 26.150^{\prime} \mathrm{S} \\
3^{\circ} 27.046^{\prime} \mathrm{E}\end{array}$ & $5161-5162$ & $\begin{array}{l}\text { 10 Jul. } 2000 \\
\text { 22:02-01:00 }\end{array}$ & $\begin{array}{l}\text { Agassiz } \\
\text { Trawl }\end{array}$ & $\begin{array}{l}\text { Eucopia grimaldii } \\
\text { Fagegnathophausia gracilis } \\
\text { Neognathophausia gigas }\end{array}$ \\
\hline $\begin{array}{c}\# 324 \\
(2)\end{array}$ & $\begin{array}{l}19^{\circ} 58.517^{\prime} \mathrm{S} \\
2^{\circ} 59.366^{\prime} \mathrm{E}\end{array}$ & - & 5493 & $\begin{array}{l}13 \text { Jul. } 2000 \\
02: 28\end{array}$ & $\begin{array}{l}\text { box corer } \\
(\mathrm{KG} 2)\end{array}$ & Siriella thompsonii \\
\hline $\begin{array}{c}\# 327 \\
(2)\end{array}$ & $\begin{array}{l}20^{\circ} 0.733^{\prime} \mathrm{S} \\
3^{\circ} 2.230^{\prime} \mathrm{E}\end{array}$ & $\begin{array}{l}20^{\circ} 6.409^{\prime} \mathrm{S} \\
3^{\circ} 7.197^{\prime} \mathrm{E}\end{array}$ & $5487-5497$ & $\begin{array}{l}\text { 15 Jul. } 2000 \\
16: 35-20: 00\end{array}$ & $\begin{array}{l}\text { Agassiz } \\
\text { Trawl }\end{array}$ & Petalophthalmus cristatus \\
\hline \#329 & $\begin{array}{l}20^{\circ} 3.520^{\prime} \mathrm{S} \\
3^{\circ} 4.710^{\prime} \mathrm{E}\end{array}$ & $\begin{array}{l}20^{\circ} 3.833^{\prime} \mathrm{S} \\
3^{\circ} 4.980^{\prime} \mathrm{E}\end{array}$ & surface & $\begin{array}{l}15 \text { Jul. } 2000 \\
18: 21-18: 33\end{array}$ & $\begin{array}{l}\text { plankton net, } \\
\text { Bongo (Bo1) }\end{array}$ & Siriella thompsonii \\
\hline $\begin{array}{c}\# 344 \\
(5)\end{array}$ & $\begin{array}{l}17^{\circ} 4.935^{\prime} \mathrm{S} \\
4^{\circ} 40.805^{\prime} \mathrm{E}\end{array}$ & $\begin{array}{l}17^{\circ} 7.454^{\prime} \mathrm{S} \\
4^{\circ} 42.276^{\prime} \mathrm{E}\end{array}$ & $5460-5460$ & $\begin{array}{l}25 \text { Jul. } 2000 \\
11: 36-15: 25\end{array}$ & $\begin{array}{l}\text { epibenthic } \\
\text { sledge }\end{array}$ & $\begin{array}{l}\text { Abyssomysis cornuta } \\
\text { Boreomysis bispinosa } \\
\text { Parapseudomma calloplura } \\
\text { Pseudomma nanum }\end{array}$ \\
\hline $\begin{array}{c}\# 348 \\
(6)\end{array}$ & $\begin{array}{c}16^{\circ} 16.989^{\prime} \mathrm{S} \\
5^{\circ} 27.279^{\prime} \mathrm{E}\end{array}$ & $\begin{array}{c}16^{\circ} 19.280^{\prime} \mathrm{S} \\
5^{\circ} 27.205^{\prime} \mathrm{E}\end{array}$ & $5430-5433$ & $\begin{array}{l}\text { 28 Jul. } 2000 \\
16: 54-20: 38\end{array}$ & $\begin{array}{l}\text { epibenthic } \\
\text { sledge }\end{array}$ & $\begin{array}{l}\text { Abyssomysis cornuta } \\
\text { Amblyops tenuicauda } \\
\text { Boreomysis bispinosa } \\
\text { Paramblyops rostratus } \\
\text { Parapseudomma calloplura }\end{array}$ \\
\hline $\begin{array}{c}\# 350 \\
(6)\end{array}$ & $\begin{array}{c}16^{\circ} 13.329^{\prime} \mathrm{S} \\
5^{\circ} 26.837^{\prime} \mathrm{E}\end{array}$ & $\begin{array}{c}16^{\circ} 14.820^{\prime} \mathrm{S} \\
5^{\circ} 26.702^{\prime} \mathrm{E}\end{array}$ & $5433-5434$ & $\begin{array}{l}\text { 29 Jul. } 2000 \\
15: 42-18: 39\end{array}$ & $\begin{array}{l}\text { epibenthic } \\
\text { sledge }\end{array}$ & $\begin{array}{l}\text { Abyssomysis cornuta } \\
\text { Paramblyops rostratus } \\
\text { Parapseudomma calloplura } \\
\text { Pseudomma nanum }\end{array}$ \\
\hline $\begin{array}{c}\# 351 \\
(6)\end{array}$ & $\begin{array}{c}16^{\circ} 25.238^{\prime} \mathrm{S} \\
5^{\circ} 27.170^{\prime} \mathrm{E}\end{array}$ & $\begin{array}{c}16^{\circ} 31.854^{\prime} \mathrm{S} \\
5^{\circ} 27.354^{\prime} \mathrm{E}\end{array}$ & $5429-5430$ & $\begin{array}{l}\text { 30.VII.00 } \\
\text { 01:57-04:57 }\end{array}$ & $\begin{array}{c}\text { Agassiz } \\
\text { Trawl }\end{array}$ & Eucopia grimaldii \\
\hline
\end{tabular}

${ }^{1}$ sampling data depicted from vial labels in combination with station list and area code in Balzer et al. (2006).

${ }^{2}$ for authorship of taxa see main text.

\section{Terminology and taxonomy}

Terminology and taxonomy as in Wittmann et al. (2014). Drawings of sex-specific features are labelled by symbols for females or males, respectively, in Figs 5-8. The absence of such labels implies absent or unapparent sex-specific differences. 


\section{Results}

Order Lophogastrida Boas, 1883

Family Gnathophausiidae Udrescu, 1984

Genus Neognathophausia Petryashov, 1992

Neognathophausia gigas (Willemoës-Suhm, 1873)

Material examined (non-type only)

ANGOLA BASIN • 1 imm. $(\mathrm{BL}=40 \mathrm{~mm}) ; 22^{\circ} 20.640^{\prime} \mathrm{S}, 3^{\circ} 23.567^{\prime} \mathrm{E}$ to $22^{\circ} 26.150^{\prime} \mathrm{S}, 3^{\circ} 27.046^{\prime} \mathrm{E}$; bottom depth 5161-5162 m; 10 Jul. 2000; DIVA-1 exped., \#321; Agassiz Trawl; ZMH 58243.

\section{Type locality}

Implicitly defined by monotypy. Willemoës-Suhm $(1873,1875)$ based the first description on a single male specimen caught between Bermuda and the Azores, $38^{\circ} 22^{\prime} \mathrm{N}, 37^{\circ} 21^{\prime} \mathrm{W}$, depth 2200 fathoms (4023 m).

\section{Distribution}

According to San Vicente (2016) this meso- to bathypelagic species shows a panoceanic distribution, latitudinal range $66^{\circ} \mathrm{N}-74^{\circ} \mathrm{S}$, depth range $650-4023 \mathrm{~m}$. This species has been reported by Illig (1930) as the synonym Gnathophausia drepanephora Holt \& Tattersall, 1905, from material taken by the "Valdivia" Expedition in the Angola Basin. See Discussion for a biogeographical assessment of the new record from 5161-5162 m bottom depth in the Angola Basin.

Genus Fagegnathophausia Petryashov, 2015

Fagegnathophausia gracilis (Willemoës-Suhm, 1875)

Material examined (non-type only)

ANGOLA BASIN $11 \mathrm{imm}$. $(\mathrm{BL}=57 \mathrm{~mm}) ; 22^{\circ} 20.640^{\prime} \mathrm{S}, 3^{\circ} 23.567^{\prime} \mathrm{E}$ to $22^{\circ} 26.150^{\prime} \mathrm{S}, 3^{\circ} 27.046^{\prime} \mathrm{E}$; bottom depth 5161-5162 m; 10 Jul. 2000; DIVA-1 exped., \#321; Agassiz Trawl; ZMH 58242.

\section{Type locality}

Implicitly defined by monotypy. Willemoës-Suhm (1875) based the first description on a single male specimen from 170 nautical miles $(315 \mathrm{~km})$ east of St. Paul's Rocks, $1^{\circ} 22^{\prime} \mathrm{N}, 2^{\circ} 36^{\prime} \mathrm{W}$, depth 1500 fathoms (2743 m).

\section{Distribution}

Circumtropical, bathypelagic, depth range 500-5225 m (Fage 1941; Clarke 1962; Vereshchaka 1990, 1995; Meland \& Aas 2013; San Vicente 2016; Hendrickx 2019). According to Clarke (1962) newly released juveniles may migrate upward to $500 \mathrm{~m}$ depth. This species has been reported by Illig (1930) as Gnathophausia gracilis Willemoës-Suhm, 1875, from material taken by the "Valdivia" Expedition in the Angola Basin. The new record from this basin extends the previously known latitudinal range of $34^{\circ} \mathrm{N}-18^{\circ} \mathrm{S}$ southward to $22^{\circ} \mathrm{S}$. See Discussion for an assessment of the vertical distribution in the Angola Basin. 
Family Eucopiidae G.O. Sars, 1885

Genus Eucopia Dana, 1855

Eucopia grimaldii H. Nouvel, 1942

Material examined (non-types only)

ANGOLA BASIN $11 \mathrm{imm}$. $(\mathrm{BL}=28.3 \mathrm{~mm}) ; 22^{\circ} 20.640^{\prime} \mathrm{S}, 3^{\circ} 23.567^{\prime} \mathrm{E}$ to $22^{\circ} 26.150^{\prime} \mathrm{S}, 3^{\circ} 27.046^{\prime} \mathrm{E}$; bottom depth 5161-5162 m; 10 Jul. 2000; DIVA-1 exped., \#321; Agassiz Trawl; ZMH 58244 2 q subad. $(B L=42.6-46.2 \mathrm{~mm}), 5 \mathrm{imm} .(B L=18.7-24.6 \mathrm{~mm})$; same collection data as for preceding; ZMH 58246 1 ㅇ ad. $(\mathrm{BL}=35.1 \mathrm{~mm}), 1$ ○ $(\mathrm{BL}=25.4 \mathrm{~mm}), 1 \mathrm{imm} .(\mathrm{BL}=17.8 \mathrm{~mm}) ; 16^{\circ} 25.238^{\prime} \mathrm{S}$, $5^{\circ} 27.170^{\prime}$ E to $16^{\circ} 31.854^{\prime} \mathrm{S}, 5^{\circ} 27.354^{\prime} \mathrm{E}$; bottom depth 5429-5430 m; 30 Jul. 2000; DIVA-1 exped., \#351; Agassiz Trawl; ZMH 58245 1 ○ $(\mathrm{BL}=31.7 \mathrm{~mm}$, in separate vial); same collection data as for preceding; SMF 55188.

\section{Type locality}

Not specified. Nouvel (1942) did not differentiate between NE- or NW-Atlantic specimens upon first description.

\section{Distribution}

This meso- to bathypelagic species shows a panoceanic distribution, mainly occurring in tropical to temperate regions, also found in the Bering Sea, Antarctica, Mediterranean, Caribbean, Gulf of Mexico, off Madagascar, $66^{\circ} \mathrm{N}-64^{\circ} \mathrm{S}$, depth range 200-4829 m (Springer \& Bullis 1956; Astthorsson 1987; Petryashov 1993, 2005a, 2005b; Ariani \& Wittmann 2005; Fukuoka 2009; Price et al. 2009; Burnham 2015; San Vicente 2010, 2016). This species will be reported by Wittmann (in press) from material taken by the "Valdivia" Expedition in the Angola Basin. See Discussion for a biogeographical assessment of the new records from 5161-5430 m bottom depth in the Angola Basin.

Order Mysida Boas, 1883

Suborder Petalophthalmida Tchindonova, 1981

Family Petalophthalmidae Czerniavsky, 1882

Subfamily Petalophthalminae Czerniavsky, 1882

Petalophthalmidae Czerniavsky, 1882: 56 (in key).

Petalophthalmidae - Tattersall \& Tattersall 1951: 113 (partim). - O.S. Tattersall 1955: 58 (partim). Murano 1971: 46. — Lagardère 1983: 814. — Tchindonova 1993: 152 (partim). — Nouvel et al. 1999: 78 (partim). — Meland \& Willassen 2007: 1096 (partim). — Fukuoka 2009: 409. — Price \& Heard 2009: 939. — Ortiz et al. 2012: 985. — Petryashov 2014: 185 (partim). — San Vicente et al. 2014: 78. - Sawamoto 2014 (partim). — Many additional references not listed.

Petalophthalminae - Wittmann et al. 2014: 331. — Meland et al. 2015: table 4. — San Vicente \& Corbari 2015: 243. - San Vicente 2017: 154. — Mees \& Meland 2019 (in database).

Petalophthalmidae Holt \& Tattersall, 1906: 21-22 (this invalid taxon erroneously described as a new one although already having been established by Czerniavsky (1882), who used the same name based on the same implicitly defined type genus).

Diagnosis (revised from Wittmann et al. 2014)

Petalophthalmidae with large antennula showing distinct sexual dimorphism; eyes normal or modified, in any case not miniaturized, visual elements present or absent; mandibular palp long, powerful, and prehensile; thoracopods 1-2 without exopod, thoracopods 3-8 with well-developed exopod; powerful 
subchelae are formed by opposition of dactylus with large claw to the propodus in thoracic endopod 1 , and to the carpopropodus in endopod 2; merus of endopod 1 with large endite; ischium of endopod 2 with again larger, subquadrangular endite; endopod 5 with more than three segments; endopods 3-4 and 6-8 normal or reduced to different degrees; well-developed oostegites on thoracopods 2-8; female pleopods uniramous or biramous, male pleopods biramous; exopod of uropods with subterminal suture.

\section{Type genus}

Petalophthalmus Willemoës-Suhm, 1874.

\section{Genera included}

Petalophthalmus Willemoës-Suhm, 1874 [4 species]

Ipirophthalmus gen. nov. [4 species]

Pseudopetalophthalmus Bravo \& Murano, 1997 [2 species]

Parapetalophthalmus Murano \& Bravo, 1998 [1 species]

\section{Distribution}

The pooled taxa of Petalophthalminae show a panoceanic distribution between $56^{\circ} \mathrm{N}$ and $46^{\circ} \mathrm{S}$, total depth range $0-5500 \mathrm{~m}$, mainly $100-500 \mathrm{~m}$.

Genus Petalophthalmus Willemoës-Suhm, 1874

Petalophthalmus Willemoës-Suhm, 1874: XIV [male only; females belong to Birsteiniamysis inermis (Willemoës-Suhm, 1874)]

Petalophthalmus - Willemoës-Suhm 1875: 43 (male only). - Perrier 1893: 1026. — Faxon 1895: 223. - Tattersall \& Tattersall 1951: 120. - Pillai 1965: 1684 (partim). - O.S. Tattersall 1968: 273 (partim). - Panampunnayil 1982: 643 (partim). - Kathman et al. 1986: 214. — Bravo \& Murano 1997a: table 1. — San Vicente \& Corbari 2015: fig. 8 (partim). — San Vicente 2017: 154. — Mees \& Meland 2019 (in database).

\section{Revised diagnosis}

Petalophthalminae with antennal scale setose all around; eyes not miniaturized, nonetheless cornea reduced, without or with some scattered visual elements, together not forming a compound sensory organ; anterior margin of carapace without pair of distinct submedian processes, rostrum present or absent; lacinia mobilis absent in one mandible, developed in the other one; pars centralis absent or reduced to one spine (tooth, digitus); thoracic endopods 3-4 reduced to 1-2 short segments; thoracic endopods 5-8 slender, with more than five segments; flagellum of thoracic exopods 3-8 with 13-21 segments; pleopods biramous in males, biramous or uniramous in females; telson large, subquadrangular, terminal margin truncate with or without slight emargination, terminal margin without or with two submedian groups of small teeth, in any case with 7-13 large, toothed spines, without setae.

\section{Type species}

Petalophthalmus armiger Willemoës-Suhm, 1875.

\section{Distribution of the species included}

Petalophthalmus armiger with panoceanic distribution, $56^{\circ} \mathrm{N}$ to $46^{\circ} \mathrm{S}$, mesopelagic to abyssobenthic, 900-4572 m depth;

Petalophthalmus cristatus sp. nov. from the SE-Atlantic, Angola Basin, depth $\leq 5497 \mathrm{~m}$; 
Petalophthalmus papilloculatus San Vicente, Frutos \& Cartes, 2014, from the NE-Atlantic, Galicia Bank off Iberian Peninsula, 1536-1809 m depth;

Petalophthalmus papuaensis San Vicente \& Corbari, 2015, from the tropical W-Pacific, Bismarck Sea, 800-1065 m depth.

\section{Petalophthalmus cristatus sp. nov. urn:1sid:zoobank.org:act:D4D691BD-4E1A-4D8B-B5A2-36979FBA2558}

Figs $1-4$

Diagnosis (based on adult female only)

Petalophthalmus with eyes elongate ovoid, dorsoventrally flattened by a factor of 1.4 ; no visual elements developed; stalk with short papilla on mesial margin. Inner margin of outer antennular flagellum subbasally with short, distally rounded, longitudinal crista. Antennal scale with distinct apical segment. Carapace with essentially transverse, centrally concave anterior margin, rostrum forms a proximally widening crista in dorsal view and an acute triangle in lateral view. Masticatory part of left mandible with well-developed lacinia mobilis, right mandible without. Mandibular palp powerful, (when stretched) anteriorly extending beyond antennular trunk; apical segment with 7 long, strong setae; apical segment half as long as median segment; basal segment with rounded lobe near disto-medial edge (dashed line in Fig. 2A). Thoracopods 1-2 without exopods; thoracopods 3, 8 with exopods bearing a 17-segmented flagellum; exopods 4-7 with 18-segmented flagellum. Merus of thoracic endopod 2 with smooth setae along outer margin. Endopods 3-4 rudimentary, unsegmented, lobe-like. Endopod 5 fully developed, slender, elongate; carpus not fused with propodus; disto-medial edge of propodus with two proximally microserrated setae (Fig. 3D); dactylus with very short, stout, terminally bent claw serrated by strong teeth. Endopods 6-8 again more slender, longer than exopods; carpus fused with propodus; dactylus with small, slightly bent, smooth claw. Female pleopods uniramous, reduced to 3 -segmented endopods, increasing in length caudally. Apical segment extremely miniaturized in pleopod 1 (Fig. 3O), well developed in pleopods 2-5. Exopod of uropod extends beyond endopod, the latter beyond telson; endopod without statocyst and spines. Exopod 2-segmented, basal segment with small, barbed seta and two spines on disto-lateral corner (Fig. 4G). Telson subquadrangular with rounded terminal edges; dense series of 23-24 spines only on distal $40 \%$ of lateral margins, proximal portions smooth. Telson almost truncate, mid-terminally emarginated by only $1 \%$ of its length. Terminal margin with short, bilaterally toothed, median spine, on each side flanked by three small teeth and again more laterally by five large, bilaterally toothed spines; the most lateral spine shorter than the sublateral one; spine length decreases from sublateral to innermost spines.

\section{Etymology}

The species name is a Latin adjective with masculine ending, referring to the longitudinal crista on the inner margin of the outer antennular flagellum and to the longitudinal median crista forming the rostrum.

\section{Material examined}

Holotype (by present designation)

ANGOLA BASIN $\bullet+$ ad. ( $\mathrm{BL}=28.3 \mathrm{~mm}$, brood pouch empty, dissected and mounted on 14 slides); SE-Atlantic, Angola Basin; $20^{\circ} 0.733^{\prime} \mathrm{S}, 3^{\circ} 2.230^{\prime} \mathrm{E}$ to $20^{\circ} 6.409^{\prime} \mathrm{S}, 3^{\circ} 7.197^{\prime} \mathrm{E}$; bottom depth $5487-$ 5497 m; 15 Jul. 2000; DIVA-1 exped., \#327; Agassiz Trawl; ZMH 58247.

\section{Type locality}

Station \#327 (Table 1) in the abyssal plain of the Angola Basin; $20^{\circ} 1^{\prime} \mathrm{S}, 3^{\circ} 2^{\prime} \mathrm{E}$ to $20^{\circ} 6^{\prime} \mathrm{S}, 3^{\circ} 7^{\prime} \mathrm{E}$; bottom depth 5487-5497 m. Sample taken with Agassiz Trawl, therefore not definitely excluded that the material entered the gear during ascent. 


\section{Description}

All features of the diagnosis. Body moderately slender, cephalothorax contributes $34 \%$ total length, pleon $46 \%$, telson $20 \%$, carapace $29 \%$.

CARAPACE (Fig. 1A-C). Leaving ultimate 1.5 thoracic somites mid-dorsally exposed; antero-lateral edges rectangular, terminally rounded; small bulge behind rostrum; cervical sulcus weak but distinct. Posterior margin of carapace emarginated; emargination unapparent upon inspection in situ (Fig. 1A-B), but well visible in carapace detached and expanded on slide (Fig. 1C).

EyEs (Fig. 1A-C). No external corneal structures visible. Definite ocular papilla on mesial margin visible in dorsal view (Fig. 1B-C) but not so in lateral view (Fig. 1A). Eyes 1/5 carapace length; dorsoventrally weakly compressed with length $5 / 2$ maximum width in dorsal view vs $7 / 2$ maximum height in lateral view. Eyes appear wider in Fig. 1C due to pressure exerted by cover glass.

Antennula (Fig. 1A-B, D-E). Trunk long and slender, 1.1 times length of carapace. Three-segmented, whereby segments $1-3$ are $46-48 \%, 35-37 \%$, and $17 \%$ total trunk length, respectively. Basal segment with small spine in subterminal position. Terminal margin of distal segment dorsally produced in a triangular, setose lobe. Width at basis of outer flagellum is $4 / 5$ that of inner flagellum. Width of longitudinal crista near basis is $1 / 4$ width of outer flagellum, length is $2 / 3$ width of outer flagellum.

Antenna (Fig. 1A-B, F). Sympod on its mesial margin with small lobe bearing a minute spine at tip. Peduncle 3-segmented, whereby segments $1-3$ contribute $9-11 \%, 40-44 \%$, and $47-49 \%$ to total peduncle length. Mesial margin of basal segment with small lobe ending in a large spine. Flagellum tiny, short, 6-segmented. Antennal scale extends slightly beyond antennal peduncle, i.e., clearly beyond basal segment of antennular trunk. Scale 0.6 times length of carapace; scale length six times maximum width. Scale subdivided by a slightly oblique articulation; apical segment $4-5 \%$ total scale length.

LABRUM (Fig. 1G-H). Roughly trapezoidal in ventral view; caudal margin densely setose, with three bunches of slender spines facing the mandibles.

Mandibles (Fig. 2A-C). Palpus $3 / 2$ length of carapace; segments 1-3 contribute $8-9 \%, 58-60 \%$, and $32-33 \%$ to total length, respectively. Basal (first) segment laterally with spine on the tip of a triangular lobe. Analogous, smaller structure set subbasally on outer margin of median segment; apart from that, outer margin smooth all along; inner margin almost all along with numerous smooth, in part spine-like, long setae with shorter ones in between. Terminal segment reflexed, together with seven very long, strong setae rendering the palpus a large prehensile appendage. Left mandible with large processus incisivus ending in three blunt teeth; lacinia mobilis well developed with four, mostly less blunt teeth; pars centralis reduced to a single finger-like process; processus molaris with weakly sclerotized ridges and with ventral and dorsal ridges of stiff bristles. Right mandible with large processus incisivus bearing three rounded lobes representing surrogates of teeth; no lacinia mobilis developed; pars centralis reduced to a finger-like process; processus molaris trilobate.

LABIUM (Fig. 2D). Normal, bilobate. Inner face of the lobes all along densely setose, with dense series of stiff bristles (short spines) extending from half to $2 / 3$ length from basis.

Maxillula (Fig. 1I-J). Small, distal segment shorter than exopod of maxilla. This segment terminally with nine unilaterally serrated spines, namely four smaller ones on caudal face plus five large ones on rostral face. No pores visible. Endite subterminally with three setae barbed along their median to subterminal portions, basal third smooth. Terminal margin of endite with two additional setae showing longer barbs from their basal to subapical portions; additional two such setae subterminally on ventral margin. 


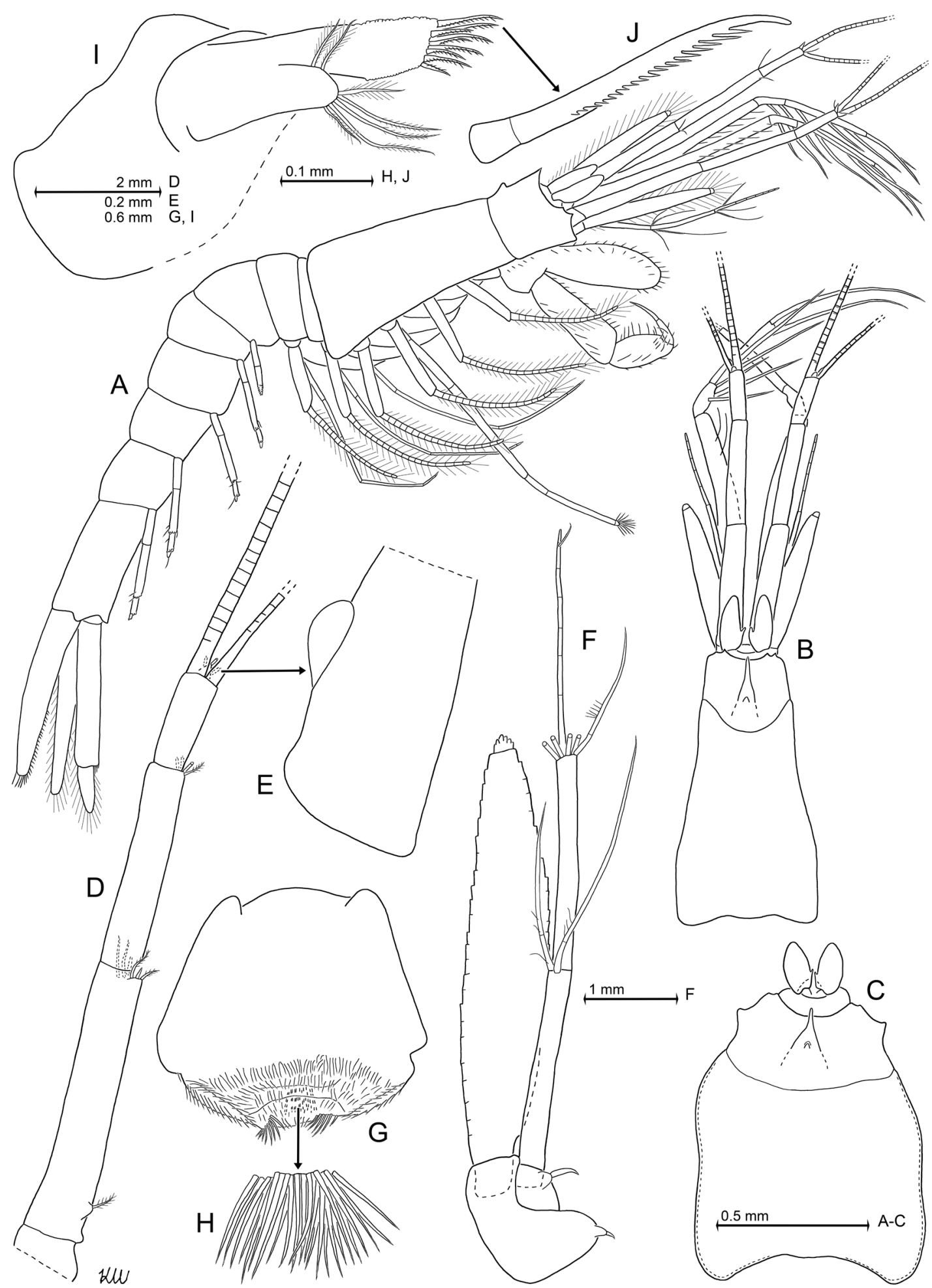

Fig. 1. Petalophthalmus cristatus sp. nov., holotype, adult female with body length $28.3 \mathrm{~mm}$ (ZMH 58247). A. Habitus. B. Anterior body region, dorsal (most setae omitted). C. Carapace with attached frons, ocular symphysis and eyes, expanded on slide. D. Antennula, ventral. E. Detail of D, below drawing plane (showing basis of outer flagellum). F. Antenna, ventral (setae of scale omitted). G. Labrum. H. Detail of G, below drawing plane (showing spine bunch from posterior face). I. Maxillula. J. Detail of I, showing serrated spine. 


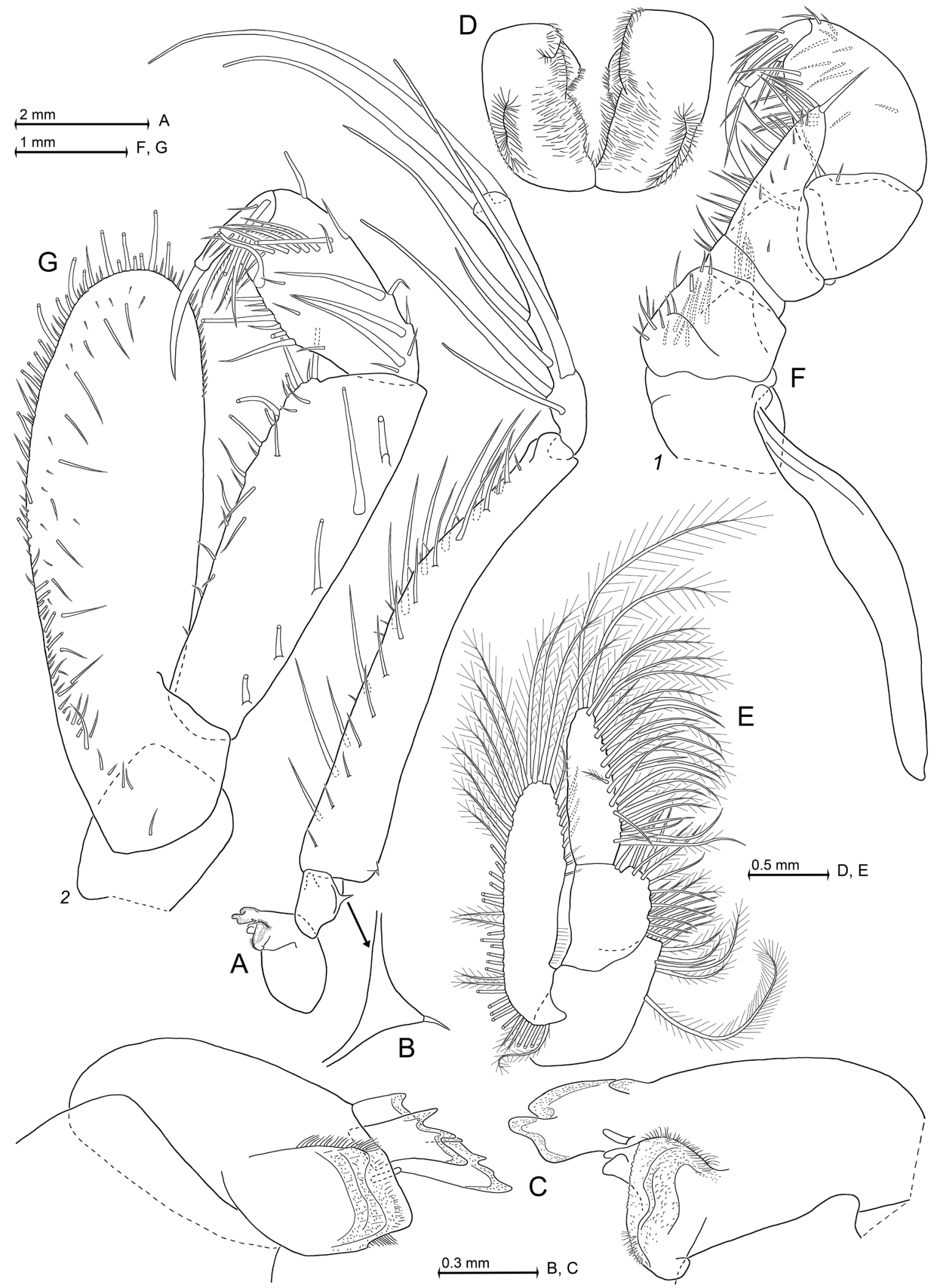

Fig. 2. Petalophthalmus cristatus sp. nov., holotype, adult female with body length $28.3 \mathrm{~mm}$ (ZMH 58247). A. Right mandible with palpus. B. Detail of A, showing outer lobe ending in a spine. C. Masticatory parts of both mandibles. D. Labium. E. Maxilla. F. Thoracopod 1. G. Endopod of thoracopod 2. 
MaXiLla (Fig. 2E). Sympod with striking, very long, barbed seta on inner face; this seta more densely barbed along its distal half; sympod with well-projecting endite, the latter setose on its distal half. Palp 2 -segmented, with stout proximal and slender distal segment; the latter contributing $60 \%$ to total length, its length three times maximum width; distal segment densely setose along distal and inner margins, outer margin smooth; its most distal setae plumose, longer than distal segment. Basal segment of palp with densely setose, weakly projecting endite. Exopod slender, length four times maximum width; exopod reaches to mid of distal segment of palp; exopod densely setose all along outer margin and on distal half of inner margin; proximal quarter of inner margin with dense series of minute hairs.

ForEgut (Fig. 4A-E). Object in Fig. 4A dorsally opened, laterally unfolded and expanded on slide; posterior half distorted. Gross morphology as described by Kobusch (1998) and De Jong-Moreau \& Casanova (2001) for Petalophthalmus armiger. Gastric mill restricted to anterior half of the cardiac portion of the foregut. Anterior part of each laterale with 29-30 smooth spines (Fig. 4C) increasing in length posteriorly. Spines in ribbon-like arrangement on posterior half of this part of the lateralia. Posterior part of the right lateralia broken in this object; left ones intact, with linear series of throughout slender spines (Fig. 4B), the spines smooth except for tuft of acute spinules at tip. Dorso-lateral infoldings of the cardia each with antero-posterior series of setae, anteriorly starting with numerous long, smooth setae, continued by shorter setae with stiff bristles on apical half, and finally by 12-14 spine-like setae with continuous gradient from basally widened, oblong setae (Fig. 4D) all along with dense series of acute bristles (spinules) to basally smooth sheets (Fig. 4E) with oblique terminal margin densely occupied by such bristles. Pyloric portion of foregut with two slender, posteriorly directed, soft processes resembling spines (below drawing plane in Fig. 4A). Foregut empty in this specimen.

Thoracopods IN GENERAL (Figs 2F-G, 3A-I). Total length of exopods as well as their flagella increase from exopod 3 to 7, whereas that of exopod 8 ranges between nos 3 and 4. Basal plate of exopods slender, lateral margins parallel, disto-lateral edge rounded; length four times width in exopods 3-7, only three in exopod 8; basal plates 3-4, 8 with roughly equal length, plates 5-7 about 1.3 times longer. Flagella densely setose. Total length decreases from endopods 5 to 8 . Dactylus $1-2,5-8$ not fused with claw (nail), endopods 3-4 without claw. Marsupium formed by seven pairs of oostegites emerging as setose epipods on thoracopods $2-8$.

FIRST THORACOPOD (first maxilliped, Fig. 2F). Epipod long, slender, smooth all around, scaphoceritelike, not contributing to the marsupium. Endopod strong, robust, densely setose on inner face from basis to dactylus; coxa with triangular endite (dashed line in Fig. 2F) on rostral face (below drawing plane); merus with large, distally projecting endite; propodus swollen, length 1.5 times maximum width; dactylus elongate, with strong, curved, smooth claw.

SECOND thoracopod (second maxilliped; Figs 1A, 2G). Epipod (if termed as such) represented by the first oostegite. Endopod robust, larger than that of the first thoracopod. Praeischium simple, smooth. Inner face of ischium with very large, broadly linguiform, subquadrangular endite with length about three times maximum width, endite distally projecting up to distal half of carpopropodus; mesial and terminal margins of endite all along with cuspidate setae; lateral margin with shorter such setae only on distal quarter, remainder smooth. Merus subquadrangular, distally widening, its length about three times maximum width; many smooth setae along inner margin, five such setae along outer margin. Carpopropodus swollen, length 1.9-2.1 times maximum width, three large and six small, smooth setae on outer margin, numerous smooth setae along inner margin, plus ten barbed setae on distal third of caudal face; dactylus elongate, with several setae and apically with strong, curved, smooth claw.

THIRD AND FOURTH THORACOPODS (Fig. 3A-B). Endopods unarmed, smooth, terminally well rounded, each only $2 / 5$ length of basal plate of respective exopod. 


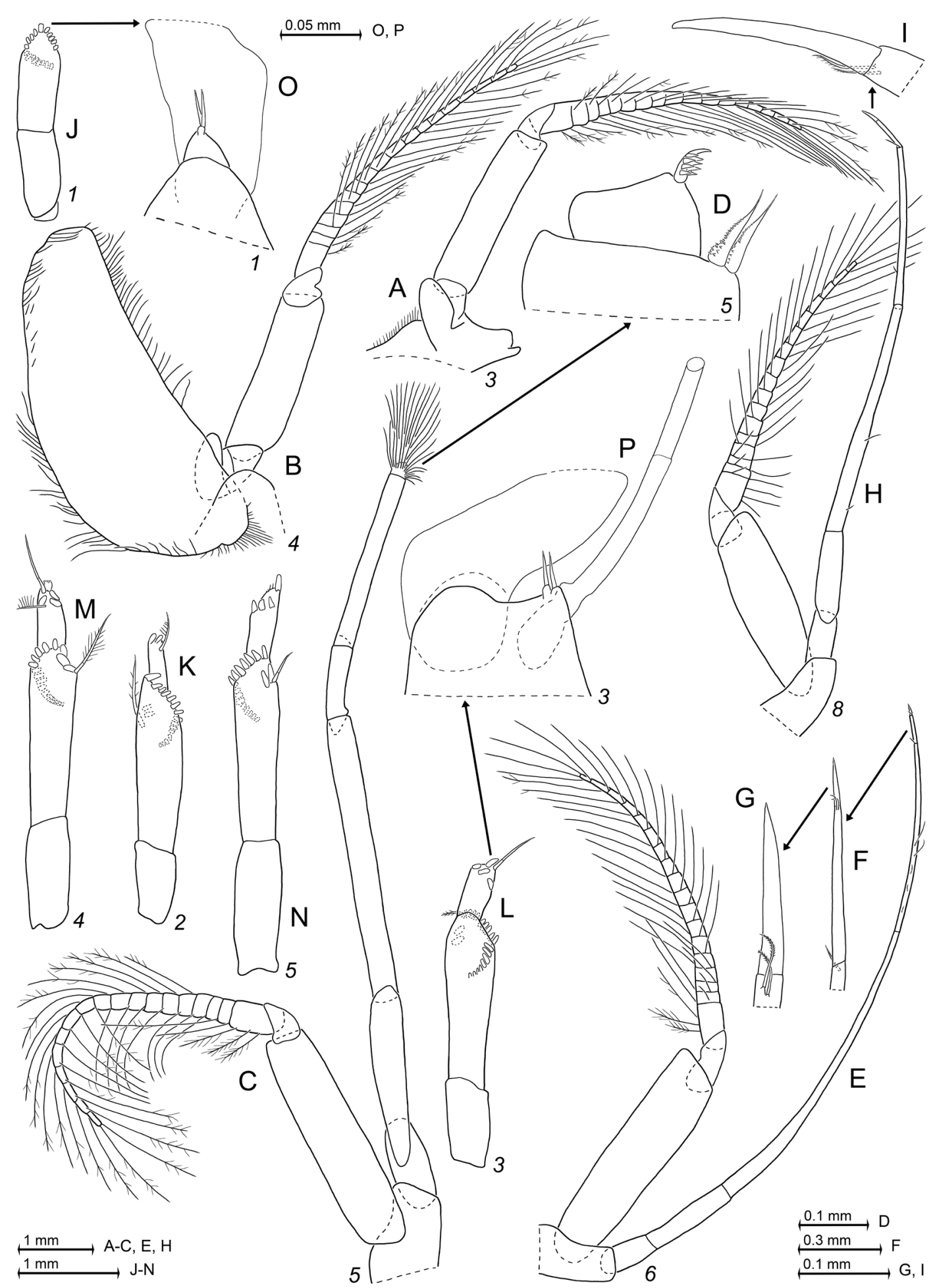

Fig. 3. Petalophthalmus cristatus sp. nov., holotype, adult female with body length $28.3 \mathrm{~mm}$ (ZMH 58247). A. Endopod and exopod of thoracopod 3. B. Thoracopod 4. C. Endopod and exopod of thoracopod 5. D. Detail of C (non-modified setae omitted), showing dactylus and distal portion of propodus. E. Endopod and exopod of thoracopod 6. F. Detail of E, showing dactylus. G. Second order detail of E, showing distal portion of dactylus with nail. H. Endopod and exopod of thoracopod 8 . I. Detail of $\mathrm{H}$, showing distal portion of dactylus with nail. J-N. Series of pleopods $1-5$, rostral (J-K, $\mathrm{M}-\mathrm{N}$ ) or caudal (L) aspect. O. Tip of pleopod 1. P. Tip of pleopod 3. 
Fifth thORACOPOD (Fig. 3C-D). Endopod 7/5 length of exopod. Endopod with praeischium 0.3 (overlapping with ischium), ischium 0.6 , carpus 0.3 , propodus 0.6 , and dactylus 0.04 times length of merus, each not subdivided (the same size relations reported by San Vicente et al. (2014), for ischium to dactylus in P. papilloculatus). The here reported size relations take into account that praeischium and ischium are overlapping due to their oblique articulation. Setation of dactylus and of terminal margin of propodus together contributing to a strong brush of setae; short claw armed with eight strong teeth (Fig. 3D). Propodus with two modified setae at disto-medial edge (Fig. 3D).

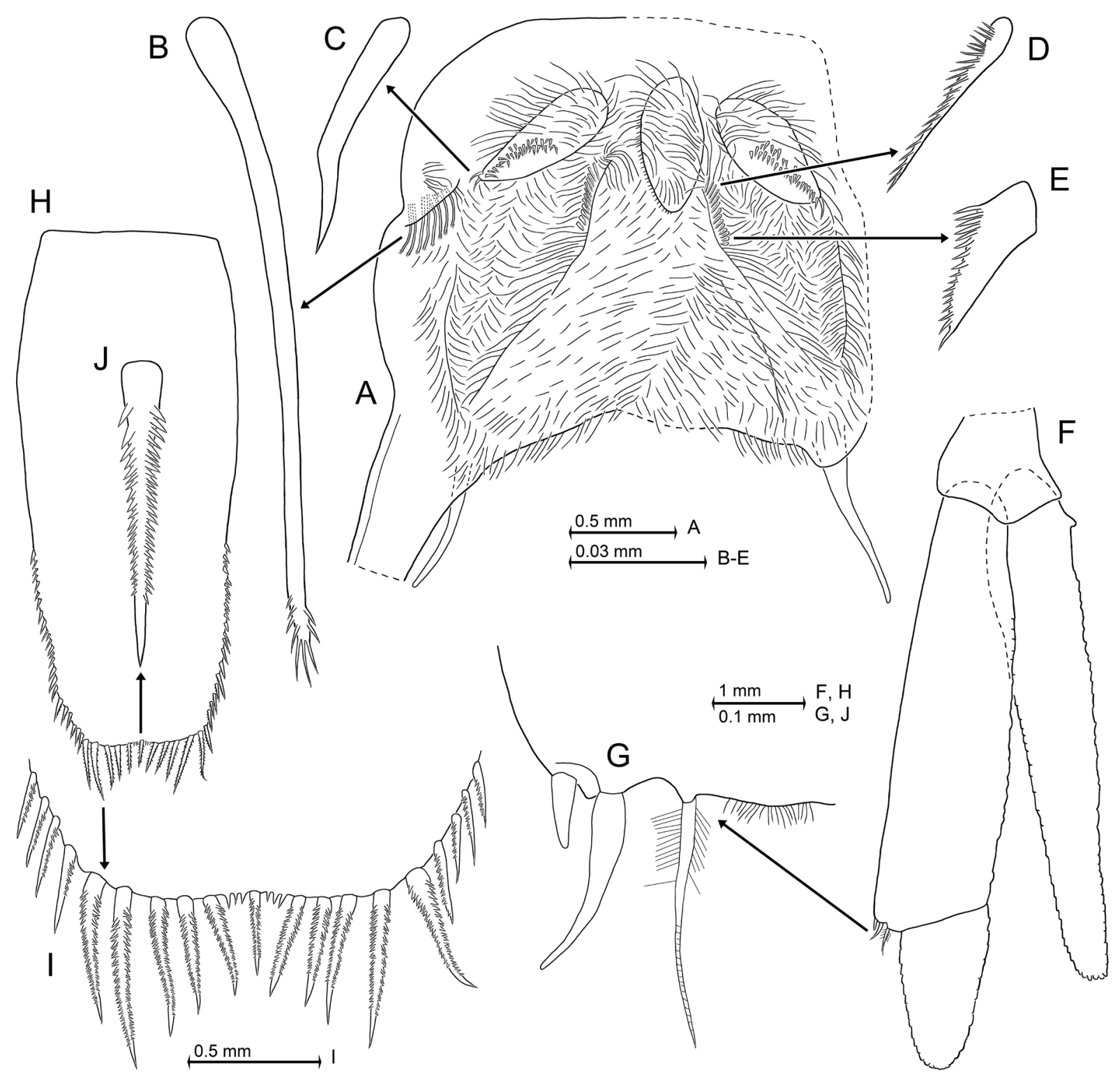

Fig. 4. Petalophthalmus cristatus sp. nov., holotype, adult female with body length $28.3 \mathrm{~mm}$ (ZMH 58247). A. Foregut dorsally opened, laterally unfolded and expanded on slide, distorted. B-E. Details of A, showing spines of gastric mill. F. Uropods. G. Detail of F, showing disto-lateral corner of basal segment of exopod. H. Telson. I-J. Details of H, showing terminal margin and medioterminal spine, respectively. 
Sixth to eighth thoracopods (Fig. 3E-I). Endopods $\% / 5$ length of exopods. Merus $6-8$ contribute $40-$ $46 \%$ to endopod length measured from praeischium to dactylus. Endopods with praeischium $0.13-0.21$, ischium $0.3-0.4$, carpopropodus $0.6-0.7$, and dactylus $0.09-0.15$ times length of merus, each element not subdivided.

Pleon (Figs 1A, 3J-P). Pleonites 1-5 measure 0.6, 0.5, 0.5, 0.5, and 0.6 times length of pleonite 6 . Apical segment of pleopods 1-5 contributes $1 \%, 17 \%, 16 \%, 18 \%, 18 \%$ to total length; median segment $54 \%, 57 \%, 57 \%, 50 \%, 47 \%$; basal segment $45 \%, 26 \%$, 27\%, 32\%, 33\%. Apical segment of pleopod 1 with a pair of minute spines on tip (Fig. 3O); pleopods 2-5 with such pair on caudo-terminal edge (Fig. 3P). Spines are $1.1-1.2 \%$ length of pleopod 1 or $0.7-0.8 \%$ of pleopods $2-5$, respectively. Median segment of all pleopods with 15-19 papillae arranged in semicircle covering part of rostral and caudal faces (Fig. 3J-N). Pleopods $2-5$ with separate pair of papillae in subterminal position on the anterior margin of median segment; other 2-5 papillae on terminal third of apical segment. Papillae much larger than spines and those setal bases present on apical segment (Fig. 3P).

UROPODS (Fig. 4F-G). Endopod slender, length six times maximum width; lateral margins straight, setose all around. Endopod as long as telson, nonetheless, due to its more caudal insertion shortly extending beyond telson (Fig. 1A). Exopod 1.15 times endopod or telson length. Exopod 2-segmented, total length five times maximum width, apical segment $1 / 4$ total length; basal segment 1.3 times broader than apical segment. Basal segment with smooth outer margin and densely setose inner margin; apical segment densely setose all around. The free latero-terminal portion of basal segment with small, smooth, blunt spine at disto-lateral corner, bordered by a threefold longer spine of that type in more mesial position, followed by an even longer, basally barbed seta, and finally a dense series of minute bristles close to insertion of apical segment (Fig. 4G).

Telson (Fig. 4H-J). Length 2.3 times maximum width or 1.5 times length of pleonite 6 . Distal $40 \%$ of each lateral margin with dense series of smooth spines except for the most distal 6-7 spines being unilaterally toothed. By contrast, all large spines of terminal margin bilaterally toothed. Terminal margin with two sets of three closely adjoining small teeth arranged in laterally increasing size, one set on each side of the bilaterally toothed, median spine (Fig. 4J).

Ipirophthalmus gen. nov.

urn:1sid:zoobank.org:act:CC361198-98AD-4399-8483-3912AA62D2A0

Petalophthalmus - Pillai 1965: 1684 (partim). - O.S. Tattersall 1968: 273 (partim). — Panampunnayil 1982: 643 (partim). — Wang 1998: 202-203. — San Vicente \& Corbari 2015: fig. 8 (partim).

\section{Type species}

Petalophthalmus liui Wang, 1998, by present designation.

\section{Etymology}

The generic name is a Latinized noun with masculine ending, formed as a condensate of the Ancient Greek adjective $\dot{\pi} \pi \eta \rho \varepsilon \tau \iota \kappa o ́ \varsigma$ (functional) with the noun $\dot{\delta} \varphi \theta \alpha \lambda \mu \dot{o} \varsigma$ (eye), underlining the difference from the reduced visual elements in the genus Petalophthalmus.

\section{Diagnosis}

Petalophthalminae with antennal scale setose all around; eyes with well-developed, functional cornea; anterior margin of carapace with rostrum flanked by a pair of processes; thoracic endopods 5-8 slender, each with more than three segments; flagellum of thoracic exopods 3-8 with 10-14 segments; male 
pleopods biramous, female pleopods uniramous or biramous; telson large, subquadrangular, terminal margin truncate without or with distinct mid-terminal emargination, terminal margin with two submedian groups of small teeth, with 7-8 large, toothed spines and 1-2 pairs of long setae, these setae arising from the emargination, if present, otherwise from homologous submedian position.

\section{Species included}

- Ipirophthalmus liui (Wang, 1998) gen. et comb. nov., recombined from Petalophthalmus liui Wang, 1998, known only from the northern South China Sea, depth 194-219 m;

- Ipirophthalmus caribbeanus (O.S. Tattersall, 1968) gen. et comb. nov., recombined from Petalophthalmus caribbeanus O.S. Tattersall, 1968, from the Caribbean, mesopelagic in 329-366 m depth;

- Ipirophthalmus oculatus (Illig, 1906) gen. et comb. nov., recombined from Petalophthalmus oculatus, Illig, 1906, from the NW-Arabian Sea, W-Indian Ocean, off Japan, mesopelagic to bathybenthic, depth $\leq 1200 \mathrm{~m}$;

- Ipirophthalmus macrops (Tchindonova \& Vereshchaka, 1991) gen. et comb. nov., recombined from Petalophthalmus macrops Tchindonova \& Vereshchaka, 1991, from the W-Indian Ocean: off Madagascar, benthopelagic in 360-555 $\mathrm{m}$ depth.

Suborder Mysida Boas, 1883

Family Mysidae Haworth, 1825

Subfamily Boreomysinae Holt \& Tattersall, 1905

Genus Boreomysis M. Sars, 1869

Boreomysis bispinosa O.S. Tattersall, 1955

Material examined (non-types only)

ANGOLA BASIN $11 \mathrm{imm}$. (BL $=8.3 \mathrm{~mm}$, eyes missing); $17^{\circ} 4.935^{\prime} \mathrm{S}, 4^{\circ} 40.805^{\prime} \mathrm{E}$ to $17^{\circ} 07.454^{\prime} \mathrm{S}$, $4^{\circ} 42.276^{\prime}$ E; bottom depth 5460-5460 m; 25 Jul. 2000; DIVA-1 exped., \#344; epinet of epibenthic sledge; ZMH $58248 \cdot 1$ o ad. (estimated $\mathrm{BL}=12.6 \mathrm{~mm}$, cephalothorax and exuvia); $16^{\circ} 16.989^{\prime} \mathrm{S}$, $5^{\circ} 27.279^{\prime}$ E to $16^{\circ} 19.280^{\prime} \mathrm{S}, 5^{\circ} 27.205^{\prime} \mathrm{E}$; bottom depth 5430-5433 m; 28 Jul. 2000; DIVA-1 exped., \#348; supranet of epibenthic sledge; ZMH 58249.

\section{Type locality}

Not stated by O.S. Tattersall (1955). On page 14 she indicated a "female type" taken off Cape Town, depth 1350-1250 m, and a "male type" NE of St. Helena, depth 1450-700 m. A rough estimate by the present author suggests that the stations are from $34^{\circ} \mathrm{S}, 17^{\circ} \mathrm{E}$ and $15^{\circ} \mathrm{S}, 5^{\circ} \mathrm{W}$, respectively.

\section{Distribution}

Previously reported from the Atlantic Ocean and from the Atlantic sector of the Southern Ocean, $51^{\circ} \mathrm{N}-54^{\circ} \mathrm{S}, 36^{\circ} \mathrm{W}-17^{\circ} \mathrm{E}$ (O.S. Tattersall 1955; Mauchline \& Murano 1977; Hargreaves 1997; Wittmann et al. 2004; Petryashov 2005b; San Vicente 2011). The animals were sampled with benthic as well as pelagic gears. The here documented records in the SE-Atlantic at $16-17^{\circ} \mathrm{S}, 5^{\circ} \mathrm{E}$ are within the already known geographical range, while the bathymetrical range of $700-4050 \mathrm{~m}$ is now extended down to $5430-5460 \mathrm{~m}$ (see also Discussion). 


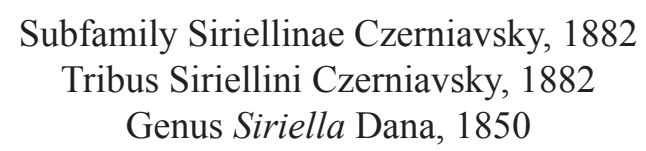

Siriella thompsonii (H. Milne Edwards, 1837)

\section{Material examined (non-types only)}

ANGOLA BASIN -2 + $q$ subad. $(\mathrm{BL}=4.8-5.0 \mathrm{~mm}), 2$ juv.; $20^{\circ} 3.520^{\prime} \mathrm{S}, 3^{\circ} 4.710^{\prime} \mathrm{E}$ to $20^{\circ} 3.833^{\prime} \mathrm{S}$, $3^{\circ} 4.980^{\prime}$ E; surface; 15 Jul. 2000; DIVA-1 exped., \#329; plankton net, Bongo (Bo1); ZMH 58271 • 1 juv. (BL $=3.1 \mathrm{~mm}$, in 2 parts); $19^{\circ} 58.517^{\prime} \mathrm{S}, 2^{\circ} 59.366^{\prime} \mathrm{E}$; bottom depth $5493 \mathrm{~m}$; 13 Jul. 2000; DIVA-1 exped., \#324; box corer (KG2); ZMH 58270.

\section{Type locality}

Not specified by H. Milne Edwards (1837), who reported this species upon first description from the North Atlantic anywhere between Madeira and the Antilles.

\section{Distribution}

Mainly circumtropical, in temperate to tropical waters of all large oceans including the Red Sea, Mediterranean, Caribbean and Gulf of Mexico, $45^{\circ} \mathrm{N}$ to $40^{\circ} \mathrm{S}$ (W.M. Tattersall 1923, 1951; O.S. Tattersall 1955, 1962; Ii 1964; Stuck et al. 1979; Price et al. 1986; Petryashov 2005a; Murano \& Fukuoka 2008; Price \& Heard 2009; Miyashita \& Calliari 2014; San Vicente 2017). Holopelagic, mainly offshore, also nearshore, mostly taken with plankton samples during the night in 0-50 m depth. Most of the population descends during the daytime down to a so far documented lower limit of $\leq 550 \mathrm{~m}$. The present record from station 329 was taken with a Bongo net at the sea surface during the day. The record from station 324 was taken during the night with a box corer closed at the bottom in $5493 \mathrm{~m}$ depth (see Discussion).

Subfamily Erythropinae Hansen, 1910

Tribus Amblyopsini Tchindonova, 1981

Genus Amblyops G.O. Sars, 1872

Amblyops tenuicauda W.M. Tattersall, 1911

Amblyops tenuicauda W.M. Tattersall 1911: 43-45, pl. 2 fig. 2, pl. 6 figs 2-8.

Amblyops tenuicauda - Illig 1930: 572 (in key). — Tattersall \& Tattersall 1951: 253, fig. 59. Mauchline \& Murano 1977: 46, table 1. - Frutos \& Sorbe 2008: online table. - San Vicente et al. 2012: 769 .

Amblyops tenuicaudus [invalid subsequent emendation] - San Vicente 2017: 160, 178, fig. 4.

\section{Nomenclatorial note}

W.M. Tattersall (1911) did not explicitly state a derivatio nominis, however he noted on page 45 "From the type it differs rather markedly in the form of the telson...". This suggests that he derived the species name from the narrow telson. Be that as it may, 'cauda' is a Classical Latin noun, while the respective adjective would be 'caudalis'. Therefore, the species name 'tenuicauda' is to be treated as an amalgamated noun in apposition rather than an adjective. According to Article 31.2.1 of the Nomenclatorial Code (ICZN 1999), a noun in apposition is to be retained, with gender ending unchanged. 
Material examined (non-types only)

ANGOLA BASIN $\bullet 7$ juvs $(\mathrm{BL}=1.8-2.6 \mathrm{~mm}) ; 22^{\circ} 19.914^{\prime} \mathrm{S}, 3^{\circ} 17.956^{\prime} \mathrm{E}$ to $22^{\circ} 20.049^{\prime} \mathrm{S}, 3^{\circ} 17.957^{\prime} \mathrm{E}$; bottom depth 5161-5162 m; 10 Jul. 2000; DIVA-1 exped., \#320; ZMH 58258 • $1 \mathrm{imm}$. (BL = $5.4 \mathrm{~mm})$; $16^{\circ} 16.989^{\prime} \mathrm{S}, 5^{\circ} 27.279^{\prime} \mathrm{E}$ to $16^{\circ} 19.280^{\prime} \mathrm{S}, 5^{\circ} 27.205^{\prime} \mathrm{E}$; bottom depth $5430-5433 \mathrm{~m}$; 28 Jul. 2000 ; DIVA-1 exped., \#348; supranet of epibenthic sledge; ZMH 58257.

\section{Type locality}

Not stated by W.M. Tattersall (1911). Upon first description, he reported materials from six stations off Ireland, NE-Atlantic, 50-52 $\mathrm{N}, 11-12^{\circ} \mathrm{W}$, depth 447-770 fathoms (817-1408 m). One additional sample was stated by him on page 44 , but accidentally omitted from the station data on page 69 , finally indirectly quoted by Tattersall \& Tattersall (1951) as pertaining to the samples from the Faroe Islands.

\section{Distribution}

Previously reported from the NE-Atlantic in the range of $44-60^{\circ} \mathrm{N}, 5-12^{\circ} \mathrm{W}$, depth $450-1408 \mathrm{~m}$ (Tattersall \& Tattersall 1951; Frutos \& Sorbe 2008; San Vicente 2017). The here documented records in the SE-Atlantic at $16-22^{\circ} \mathrm{S}, 3-5^{\circ} \mathrm{E}$, depth $5161-5433 \mathrm{~m}$, represent large extensions of the known geographical as well as bathymetrical ranges (see also Discussion).

Genus Paramblyops Holt \& Tattersall, 1905

Paramblyops rostratus Holt \& Tattersall, 1905

\section{Material examined (non-types only)}

ANGOLABASIN $\bullet 1 \delta^{\lambda}$ ad. ( $\mathrm{BL}=16 \mathrm{~mm}$, in 2 parts); $22^{\circ} 19.978^{\prime} \mathrm{S}, 3^{\circ} 18.342^{\prime} \mathrm{E}$ to $22^{\circ} 20.249^{\prime} \mathrm{S}, 3^{\circ} 18.439^{\prime}$ E; bottom depth 5179-5180 m; 9 Jul. 2000; DIVA-1 exped., \#318; ZMH 58261 • $1 \mathrm{imm}$. (BL $=9.0 \mathrm{~mm}$, in 2 parts), 1 juv. $(\mathrm{BL}=6.5 \mathrm{~mm}) ; 16^{\circ} 16.989^{\prime} \mathrm{S}, 5^{\circ} 27.279^{\prime} \mathrm{E}$ to $16^{\circ} 19.280^{\prime} \mathrm{S}, 5^{\circ} 27.205^{\prime} \mathrm{E}$; bottom depth 5430-5433 m; 28 Jul. 2000; DIVA-1 exped., \#348; supranet of epibenthic sledge; ZMH 58259 - 2 우우 imm. $(\mathrm{BL}=6.5-8.3 \mathrm{~mm})$; same collection data as for preceding; ZMH 58260 1 ㅇ subad. $(\mathrm{BL}=14.5 \mathrm{~mm}) ; 16^{\circ} 13.329^{\prime} \mathrm{S}, 5^{\circ} 26.837^{\prime} \mathrm{E}$ to $16^{\circ} 14.820^{\prime} \mathrm{S}, 5^{\circ} 26.702^{\prime} \mathrm{E}$; bottom depth $5433-5434 \mathrm{~m}$; 29 Jul. 2000; DIVA-1 exped., \#350; supranet of epibenthic sledge; SMF 55191.

\section{Type locality}

Not stated by Holt \& Tattersall (1905). Upon first description, they reported material from seven stations at the NE-Atlantic slope, depth 181-382 fathoms (331-699 m). A rough estimate by the present author suggests that the stations are in the range of $50-54^{\circ} \mathrm{N}, 10-13^{\circ} \mathrm{W}$.

\section{Distribution}

Previously reported from the North Atlantic and Mediterranean, $34-61^{\circ} \mathrm{N}, 72^{\circ} \mathrm{W}-14^{\circ} \mathrm{E}$, depth 200 2900 m (Hansen 1908, 1927; W.M. Tattersall 1909, 1951; Colosi 1929; Lagardère 1972; Nouvel \& Lagardère 1976; Mauchline 1986; Cartes \& Sorbe 1995; Cartes et al. 2004; Vanquickelberghe 2004; Fanelli 2007; Petryashov 2009; San Vicente 2010, 2017; Sorbe \& Elizalde 2013). Sorbe \& Elizalde (2013) considered this species as part of the suprabenthic fauna. The here documented records in the SEAtlantic at $16-22^{\circ} \mathrm{S}, 3-5^{\circ} \mathrm{E}$, depth 5179-5434 $\mathrm{m}$, represent large extensions of the known geographical as well as bathymetrical ranges (see also Discussion).

\section{Statoliths}

Statoliths mineralized with fluorite; diameter $124 \mu \mathrm{m}$ in the $\delta$ ad. $16 \mathrm{~mm}$, vs $89 \mu \mathrm{m}$ in the 9 subad. $14.5 \mathrm{~mm}$, and $62 \mu \mathrm{m}$ in the imm. $9.0 \mathrm{~mm}$ (2 statoliths per specimen examined). 
Tribus Pseudommini Wittmann, Ariani \& Lagardère, 2014

Genus Pseudomma G.O. Sars, 1870

Pseudomma nanum (Holt \& Tattersall, 1906)

\section{Material examined (non-types only)}

ANGOLABASIN $\bullet 1 \mathrm{imm}$. $(\mathrm{BL}=7.2 \mathrm{~mm}) ; 17^{\circ} 4.935^{\prime} \mathrm{S}, 4^{\circ} 40.805^{\prime} \mathrm{E}$ to $17^{\circ} 07.454^{\prime} \mathrm{S}, 4^{\circ} 42.276^{\prime} \mathrm{E}$; bottom depth 5460-5460 m; 25 Jul. 2000; DIVA-1 exped., \#344; epinet of epibenthic sledge; ZMH 58262 • $1 \mathrm{imm}$. (BL $=6.8 \mathrm{~mm}) ; 16^{\circ} 13.329^{\prime} \mathrm{S}, 5^{\circ} 26.837^{\prime} \mathrm{E}$ to $16^{\circ} 14.820^{\prime} \mathrm{S}, 5^{\circ} 26.702^{\prime} \mathrm{E}$; bottom depth $5433-$ 5434 m; 29 Jul. 2000; DIVA-1 exped., \#350; epinet of epibenthic sledge; SMF 55192.

\section{Type locality}

Not explicitly stated by Holt \& Tattersall (1906). On page 36 they indicated "length of the type female $8 \mathrm{~mm}$, of the type male (adult) $6.5 \mathrm{~mm}$ ". Such body sizes fit only with the material listed by them on pages $37-38$ as having been caught off Ireland, 48-50 nautical miles (89-93 km) WNW of Tearaght, depth 360387 fathoms $\left(658^{-708} \mathrm{~m}\right)$. Coordinates roughly estimated by the present author as $52^{\circ} 24^{\prime} \mathrm{N}, 11^{\circ} 54^{\prime} \mathrm{W}$.

\section{Distribution}

Previously reported from the NE-Atlantic and Mediterranean, $38-62^{\circ} \mathrm{N}, 12^{\circ} \mathrm{W}-21^{\circ} \mathrm{E}$, depth $360-2200 \mathrm{~m}$ (W.M. Tattersall 1911; Nouvel \& Lagardère 1976; Mauchline 1986; Gordon \& Duncan 1987; Meland \& Brattegard 1995; Madurell \& Cartes 2003; Sorbe \& Elizalde 2013; Petryashov 2014; San Vicente 2017). Madurell \& Cartes (2003) considered this species as suprabenthic. The here documented records in the SE-Atlantic at $16-17^{\circ} \mathrm{S}, 5^{\circ} \mathrm{E}$, depth $5433-5460 \mathrm{~m}$, represent strong extensions of the known geographical as well as bathymetrical ranges (see also Discussion).

Genus Parapseudomma Nouvel \& Lagardère, 1976

Parapseudomma calloplura (Holt \& Tattersall, 1905)

\section{Material examined (non-types only)}

ANGOLA BASIN $\bullet 1$ q ad. $(\mathrm{BL}=20.0 \mathrm{~mm}) ; 22^{\circ} 19.978^{\prime} \mathrm{S}, 3^{\circ} 18.342^{\prime} \mathrm{E}$ to $22^{\circ} 20.249^{\prime} \mathrm{S}, 3^{\circ} 18.439^{\prime} \mathrm{E}$; bottom depth 5179-5180 m; 9 Jul. 2000; DIVA-1 exped., \#318; ZMH 58263・1 9 ad. (BL $=23.3 \mathrm{~mm}$, head missing); $22^{\circ} 19.914^{\prime} \mathrm{S}, 3^{\circ} 17.956^{\prime} \mathrm{E}$ to $22^{\circ} 20.049^{\prime} \mathrm{S}, 3^{\circ} 17.957^{\prime} \mathrm{E}$; bottom depth $5161-5162 \mathrm{~m}$; 10 Jul. 2000; DIVA-1 exped., \#320; ZMH $58264 \cdot 2 \mathrm{imm}$. (damaged, $\mathrm{BL}=6.1-7.0 \mathrm{~mm}$ ); $17^{\circ} 4.935^{\prime} \mathrm{S}$, $4^{\circ} 40.805^{\prime} \mathrm{E}$ to $17^{\circ} 07.454^{\prime} \mathrm{S}, 4^{\circ} 42.276^{\prime} \mathrm{E}$; bottom depth $5460-5460 \mathrm{~m}$; 25 Jul. 2000; DIVA-1 exped., \#344; ZMH 58266 • $1 \mathrm{imm}$. (BL $=9.4 \mathrm{~mm}$, in separate vial); same collection data as for preceding; ZMH 58265 1 q subad. $(\mathrm{BL}=21.1 \mathrm{~mm}), 1$ q subad. $(\mathrm{BL}=\mathrm{ca} .14 \mathrm{~mm}$, with tailfan missing); same collection data as for preceding; ZMH $58267 \bullet 1$ o subad. $(\mathrm{BL}=17.2 \mathrm{~mm})$; same collection data as for preceding; ZMH $58268 \cdot 1 \mathrm{q}$ ad. ( $\mathrm{BL}=17.3 \mathrm{~mm}$, head missing); $16^{\circ} 16.989^{\prime} \mathrm{S}, 5^{\circ} 27.279^{\prime} \mathrm{E}$ to $16^{\circ} 19.280^{\prime} \mathrm{S}, 5^{\circ} 27.205^{\prime} \mathrm{E}$; bottom depth 5430-5433 m; 28 Jul. 2000; DIVA-1 exped., \#348; SMF 55193 - $1 \mathrm{O}^{\prime} \mathrm{imm}$. $(\mathrm{BL}=11.2 \mathrm{~mm}) ; 16^{\circ} 13.329^{\prime} \mathrm{S}, 5^{\circ} 26.837^{\prime} \mathrm{E}$ to $16^{\circ} 14.820^{\prime} \mathrm{S}, 5^{\circ} 26.702^{\prime} \mathrm{E}$; bottom depth 5433-5434 m; 29 Jul. 2000; DIVA-1 exped., \#350; ZMH 58269.

\section{Type locality}

Not stated by Holt \& Tattersall (1905). They reported materials from four stations off Ireland, depth 199-382 fathoms (363-696 m). A rough estimate by the present author suggests that the stations are in the range of $52-54^{\circ} \mathrm{N}, 12-13^{\circ} \mathrm{W}$. 


\section{Distribution}

Previously reported from the NE-Atlantic and Mediterranean, $35-58^{\circ} \mathrm{N}, 13^{\circ} \mathrm{W}-14^{\circ} \mathrm{E}$, depth $94-1200 \mathrm{~m}$, and from the NW-Pacific off Japan, 35-37 ${ }^{\circ} \mathrm{N}, 137-140^{\circ}$ E, depth 220-660 m (W.M. Tattersall 1909, 1911; Colosi 1929; Băcescu 1941, 1989; Murano 1974; Nouvel \& Lagardère 1976; Mauchline \& Murano 1977; Mauchline 1986; Cartes \& Sorbe 1995; Cartes et al. 2003; Frutos \& Sorbe 2013; Sorbe \& Elizalde 2013; San Vicente 2017). Frutos \& Sorbe (2013) sampled this species in the near-bottom water layer. The here documented records in the SE-Atlantic at $16-22^{\circ} \mathrm{S}, 3^{-} 5^{\circ} \mathrm{E}$, depth $5161-5460 \mathrm{~m}$, represent a strong extension of the known bathymetrical range; within the Atlantic also a strong southward extension (see Discussion).

\section{Statoliths}

Statoliths mineralized with fluorite, diameter $133-169 \mu \mathrm{m}$ ( $\mathrm{n}=6$ statoliths of 3 adults).

Tribus Calyptommini W.M. Tattersall, 1909

Calyptomminae W.M. Tattersall 1909: 137.

Calyptomminae - W.M. Tattersall 1911: 59-60 (definition).

Erythropini - Illig 1930: 572 (in key, partim). — Tattersall \& Tattersall 1951: 186 (partim). — Mauchline 1980: 21 (partim). — Tchindonova 1981: 26 (partim).

Leptomysini - Mauchline 1980: 22 (partim).

Calyptommini - Nouvel et al. 1999: 79. - Meland \& Willassen 2007: 1093, table 1, fig. 3 (molecular phylogeny). - Wittmann et al. 2014: 337 (definition). - Meland et al. 2015: 18, table 3 (classification). - San Vicente 2017: 161.

\section{Diagnosis}

Revised from Wittmann et al. (2014) in order to receive Abyssomysis gen. nov. Eyeplate without distinct median cleft, plate mainly formed by a transverse median bridge, eyes rudimentary or absent. Antennal scale well developed, its smooth outer margin ending in a tooth; antennal gland hypertrophic. Labrum normal, symmetrical. Females with 2-3 pairs of oostegites. Pleopods uniramous, reduced to unsegmented endopods in both sexes, except that the fourth male pleopod may be sub-segmented in certain species. Uropods normal. Telson entire, lateral margins not serrated but for the most part or entirely smooth, terminal portions with spines, no setae.

\section{Type genus}

Calyptomma W.M. Tattersall, 1909.

\section{Inventory}

Three genera with a total of five species are now included: Calyptomma W.M. Tattersall, 1909, with only the nominotypical species C. puritani W.M. Tattersall, 1909, and Michthyops W.M. Tattersall, 1911, with M. parvus (Vanhöffen, 1897), M. theeli (Ohlin, 1901) and M. arcticus Petryashov, 1993, finally the below described Abyssomysis gen. nov. with its only species A. cornuta gen. et sp. nov.

\section{Distribution}

The species of Calyptomma and Michthyops are mostly bathybenthic, living on or close to the sea floor of the Arctic Ocean, North Atlantic and Mediterranean. Only M. theeli has been found in a wider depth range of 27-2245 $\mathrm{m}$. With the below records of $A$. cornuta gen. et sp. nov. the geographical range of the 
tribe is extended to $17^{\circ} \mathrm{S}$ in the SE-Atlantic, and the bathymetrical range to the abyssobenthos down to $5460 \mathrm{~m}$ depth. For additional distribution data see key to species below.

\author{
Abyssomysis gen. nov. \\ urn:1sid:zoobank.org:act:41771FE0-7B94-4422-803C-C4B2292B9BAF
}

\title{
Type species
}

Abyssomysis cornuta gen. et sp. nov. by monotypy and present designation.

\section{Diagnosis}

Calyptommini with eyeplate formed by a transverse, median lamina (= ocular symphysis) connecting separate, rudimentary eyestalks; lamina not incised, visual elements absent. Carapace normal, anteriorly rounded. Antennula with well-developed, setose appendix masculina; proximal segment of trunk without ventral carina. Antennal sympod without spiniform extension; antennal scale well developed, entire, its smooth outer margin ending in a prominent tooth, terminal lobe well-developed. Labrum with small, knob-like rostral process. Mandibles with distinct molar part; lacinia mobilis present on left mandible, absent or vestigial on right mandible. First thoracopods normal; basis of endopod with long, setose endite. Females with three pairs of functional oostegites. Penes normal. Pleopods of both sexes reduced to unsegmented, plate- or rod-like endopods, except that the fourth male pleopod is sub-segmented. Both rami of the uropods unsegmented, setose all around, without spines. Telson short, terminally truncate; lateral margins smooth, terminal margin with spines.

\section{Etymology}

The generic name is an amalgamated noun with female ending, referring to the occurrence of this mysid in the abyssal plain.

\author{
Abyssomysis cornuta gen. et sp. nov. \\ urn:lsid:zoobank.org:act:A4017620-6EAC-4567-A3EB-BDF006954C63
}

Figs 5-8

\section{Diagnosis}

Abyssomysis gen. nov. with eyeplate in the form of a narrow, transverse band with lateral, apically acute or narrowly rounded rudiments of the eyestalks resembling horns. Anterior margin of carapace evenly rounded, upturned on the edge, forming a weakly separated rim as a rostral plate. Only distal portions of the eye rudiments extend beyond the rostral plate. Antennular trunk longer than antennal scale in males, shorter than scale in females. Male trunk with comparatively large appendix masculina bearing a dense brush of long setae. Antennal peduncle not reaching beyond antennal scale in females, whereas reaching well beyond in males. Left mandible with lacinia mobilis well developed in both sexes. Right mandible without lacinia mobilis in females, but with lacinia reduced to a tiny, slender, apically toothed spine in males (Fig. 6D). Median segment of palpus of both mandibles with only three setae in terminal position, remaining portions of palpus smooth in females, whereas distal $2 / 3$ of the median segment showing dense series of at least 14 setae in males. Females with pleopods 1-5 continuously increasing in length caudally. Males with pleopods 1-3, 5 increasing in length caudally, pleopod 4 is not in series by being the longest; fourth pleopod 3-segmented, its basal segment contributes $4 / 5$ pleopod length, the two apical segments each $1 / 10$. Pleomere 6 longer than combined pleomeres $4-5$. Telson $0.3-0.4$ times length of pleomere 6; telson length 1.0-1.1 times maximum width near basis; terminal margin with two pairs of large, robust spines; outer robust spines shorter than inner ones. 


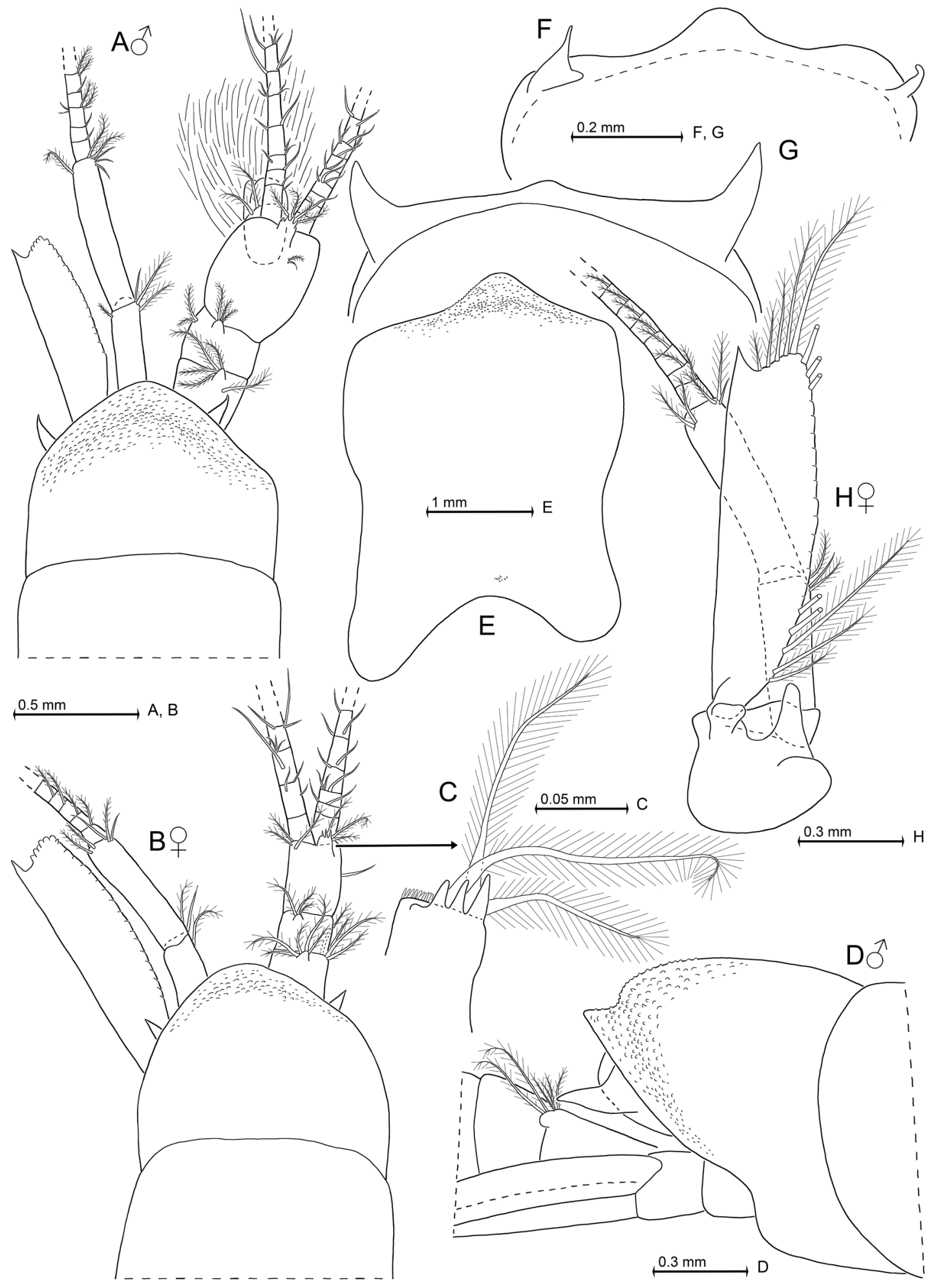

Fig. 5. Abyssomysis cornuta gen. et sp. nov., holotype, adult male with body length $6.6 \mathrm{~mm}$ (A: ZMH 58250), paratypes female $7.9 \mathrm{~mm}$ (B-C, E-F, H: ZMH 58256) and male $6.7 \mathrm{~mm}$ (D, G: ZMH 58254). A-B. Cephalic region of male (A) and female (B), dorsal; left antennula, right antenna and setae of antennal scale omitted. C. Detail of panel (B) showing lobe from terminal segment of antennula. D. Head in lateral view, setae of antennal scale omitted. E. Carapace expanded on slide. F-G. Eyeplate expanded on slide, for female (F) and male (G). H. Antenna, dorsal. 


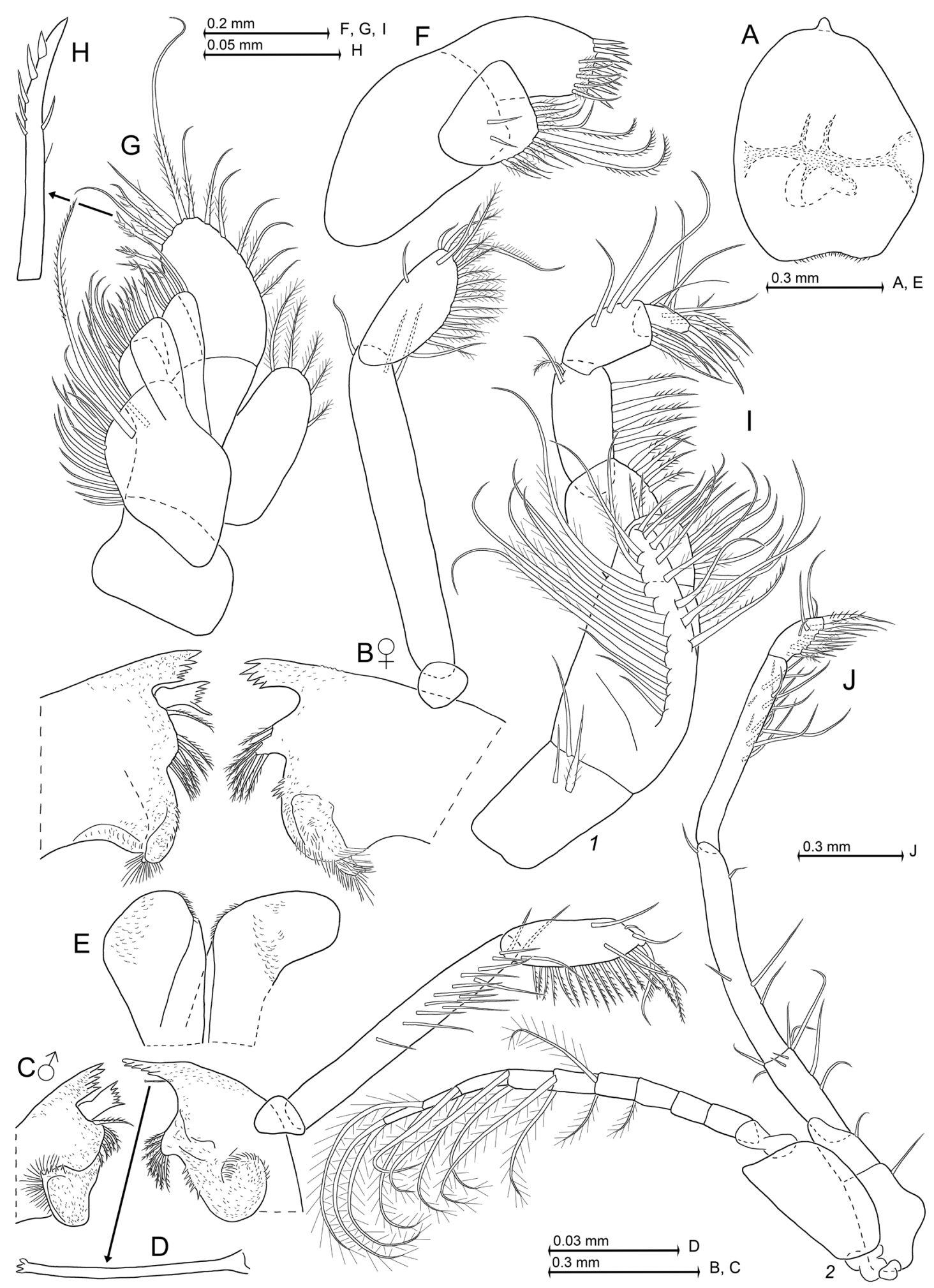

Fig. 6. Abyssomysis cornuta gen. et sp. nov., paratypes female with body length $7.9 \mathrm{~mm}$ (A-B, E-F, I: ZMH 58256) and males $6.7 \mathrm{~mm}$ (C-D, G-H: ZMH 58254), $6.8 \mathrm{~mm}$ (J: SMF 55190). A. Labrum. B-C. Mandibles with right palpus in female (B) and male (C), rostral. D. Detail of panel (C) showing reduced lacinia mobilis in right mandible of male. E. Labium. F. Maxillula. G. Maxilla. H. Detail of G showing modified spine-seta. I. First thoracic endopod. J. Second thoracopods. 


\section{Etymology}

The species name is a Latin adjective with female ending, referring to the pronged eyeplate, well contrasting from that in the remaining Calyptommini so far known.

Type material examined (by present designation)

\section{Holotype}

ANGOLA BASIN $\bullet{ }^{\prime}$ ad. $(\mathrm{BL}=6.6 \mathrm{~mm}) ; 16^{\circ} 13.329^{\prime} \mathrm{S}, 5^{\circ} 26.837^{\prime} \mathrm{E}$ to $16^{\circ} 14.820^{\prime} \mathrm{S}, 5^{\circ} 26.702^{\prime} \mathrm{E}$; bottom depth 5433-5434 m; 29 Jul. 2000; DIVA-1 exped., \#350; supranet of epibenthic sledge; ZMH 58250.

\section{Paratypes}

ANGOLA BASIN $\bullet 1$ đad. (BL $=6.7 \mathrm{~mm}$, on slides); same collection datas as for holotype; ZMH 58254 - 1 q ad. (BL $=7.9 \mathrm{~mm}$ on slides); same collection datas as for holotype; ZMH $58256 \cdot 1$ o ad. $(\mathrm{BL}=6.1 \mathrm{~mm}$, in vial), 1 i imm. (damaged, $\mathrm{BL}=6.7 \mathrm{~mm}$, in vial); same collection datas as for holotype; ZMH $58255 \cdot 1$ क ad. $\left(\mathrm{BL}=8.0 \mathrm{~mm}\right.$ in vial); $17^{\circ} 4.935^{\prime} \mathrm{S}, 4^{\circ} 40.805^{\prime} \mathrm{E}$ to $17^{\circ} 07.454^{\prime} \mathrm{S}$, $4^{\circ} 42.276^{\prime}$ E; bottom depth 5460-5460 m; 25 Jul. 2000; DIVA-1 exped., \#344; SMF 55189 1 त imm. $(\mathrm{BL}=3.4 \mathrm{~mm}$, on slides); same collection data as for preceding; ZMH $58251 \cdot 1$ o ad. (damaged, estimated $\mathrm{BL}=7.0 \mathrm{~mm}$, in vial); $16^{\circ} 16.989^{\prime} \mathrm{S}, 5^{\circ} 27.279^{\prime} \mathrm{E}$ to $16^{\circ} 19.280^{\prime} \mathrm{S}, 5^{\circ} 27.205^{\prime} \mathrm{E}$; bottom depth 5430-5433 m; 28 Jul. 2000; DIVA-1 exped., \#348; ZMH 58253 1 ô ad. (BL $=6.8 \mathrm{~mm}$, on slides); same collection data as for preceding; SMF 55190 1 + $\mathrm{imm}$. (damaged, $\mathrm{BL}=5.4 \mathrm{~mm}$, in vial); same collection data as for preceding; ZMH 58252.

\section{Type locality}

Station \#350 (Table 1) in the abyssal plain of the Angola Basin, $16^{\circ} 14^{\prime} \mathrm{S}, 5^{\circ} 27^{\prime} \mathrm{E}$, depth $5433-5434 \mathrm{~m}$.

\section{Description of the holotype (Fig. 5A)}

All diagnostic features of males. Body length $6.6 \mathrm{~mm}$, specimen not dissected. Cephalothorax without rostrum measures $40 \%$ body length, pleon without telson $51 \%$. The great contribution by the pleon is largely due to the elongate sixth pleomere. Carapace including rostrum measures $38 \%$ body length. Carapace weakly inflated, with distinct cervical sulcus, anterior third of cephalic portion with knobbly cuticle. Carapace posteriorly emarginated, leaving half of ultimate thoracomere dorsally exposed. Eyes without visual elements. Small, horn-like rudiments of eyestalks widely set apart on a common eyeplate probably homologous to the ocular symphysis. Eyeplate dorsally covered by rostral plate, only part of eyestalk rudiments projecting from behind the rostrum in dorsal view.

Antennae Sensu lato (Fig. 5A). Antennular trunk is $15 \%$ body length. Trunk 1.1 times antennal scale length. Trunk conical with distally increasing width. Terminal segment is $1.4-1.5$ times width of basal segment. Transverse articulations between the three segments of the trunk. Segments 1-3 contribute $35 \%, 20 \%$, and $45 \%$ to total trunk length, respectively. Appendix masculina inserts ventrally behind inner flagellum, appendix $1 / 3$ trunk length, its setae up to $2 / 3$. Basal segment of antennular trunk not produced at outer distal corner. Setose lobe dorsally in about median position shortly behind the anterior margin of each segment. Lobe of distal segment with four barbed setae and transverse series of four forward projecting teeth. Tooth size increases laterally. Antennal scale $1 / 7$ body length; its length four times maximum width. Apical lobe contributes $7 \%$ to total scale length, lobe wider than long, with seven plumose setae. Antennal peduncle $6 / 5$ scale length, segments $1-3$ are $0.1,0.4$, and 0.5 times peduncle length, respectively. Sympod with long, linguiform, terminally rounded lobe on dorsal face.

MouthPARTS. Mandibular palpus slender. Its proximal segment, short, smooth all around. Median segment contributing $3 / 5$ to palpus length. Distal $2 / 3$ of median segment with dense series of obliquely 
outward-backward projecting setae. Distal segment with dense comb of setae. Terminal segment three times as long as wide, $1 / 3$ palp length.

THORACOPODS. Endopod 2 large, carpus and propodus fused, dactylus with medially projecting brush of barbed setae. Sympods 3-8 with anteriorly facing, terminally rounded lobe close to (broken) insertion of praeischium of endopod (basis fused with sympod). Paired penes short, knob-like.

Pleon (Fig. 7D). Sixth pleomere $1 / 6$ body length. Pleomeres 1-5 are $0.3-0.4$ times length of pleomere 6. Scutellum paracaudale sinusoid, evenly rounded. Pleopods with setose edge as found in most species of the subfamily Erythropinae. Pleopods 1-3 reduced to setose plates, pleopods 4-5 to setose rods. Pleopod 4, when stretched posteriorly, reaches to the distal seventh of pleonite 6 . Tip of pleopod 4 with two setae. The larger seta about as long as the combined two distal segments. Median and basal segments each ending in a pair of shorter setae. Basal segment with two additional setae in subterminal position and other about eight setae $1 / 3$ segment length from basis. Uropods setose all around, exopod terminally rounded, endopod about as long as exopod, each 1.2 times length of sixth pleomere, and extending 0.7 times their length beyond telson. Telson with smooth lateral margins. Potential presence of a minute median tooth (as in some paratypes, Fig. 7I) on terminal margin could not be checked without dissection. The inner robust spines on terminal margin measure $45 \%$ telson length, the outer ones 37\%. For additional details of telson see above Diagnosis and below Description of paratypes.

\section{Description of paratypes}

Body length of adult females 7.0-8.0 mm $(\mathrm{n}=3)$, males $6.1-6.8 \mathrm{~mm}(\mathrm{n}=4$, including holotype). Cephalothorax without rostrum measures $32-40 \%$ body length, pleon without telson $51-56 \%$. Carapace including rostrum measures $31-38 \%$ body length. Carapace leaving posterior $0.5-1.0$ thoracomere dorsally exposed. Carapace with distinct cervical sulcus in situ; sulcus not visible in detached carapaces. No pores $(>1 \mu \mathrm{m})$ on carapace.

Antennae Sensu lato (Fig. 5A-C, H). Antennular trunk strongly dimorphic, size is $10 \%$ body length in females, $15-17 \%$ in males. Trunk $0.7-0.8$ times antennal scale length in females, 1.1-1.2 in males. Trunk almost cylindrical in females, whereas conical with distally increasing width in males. Terminal segment is $0.8-1.0$ times width of basal segment in females, 1.3-1.4 in males. Segments 1-3 contribute $43-46 \%, 19-20 \%$, and $35-39 \%$ to total trunk length in females; $32-38 \%, 18-20 \%$, and $43-50 \%$ in males, respectively. Antenna (Fig. 5H) non-dimorphic, scale length 3-6 times maximum width. Apical lobe contributes $5-9 \%$ to total scale length, lobe with $6-8$ plumose setae. Antennal peduncle $0.9-1.0$ times scale length in females, $1.1-1.3$ in males.

MouthParts (Fig. 6A-H). Labrum with frontal lobe bearing a small sinusoid rostral extension; the two posterior lobes terminally with median field of minute, stiff bristles, dorsally with cuticular ridges (dashed lines in Fig. 6A). Median segment of mandibular palpus 5-6 times as long as wide. Pars incisiva of both mandibles with 5-6 moderately sized teeth, processus molaris strongly cuticularized. Lacinia mobilis of left mandible with six teeth; for right lacinia see Diagnosis. Pars centralis of left mandible with 6-7 'spines' bearing stiff bristles or denticles. Right centralis with 8-9 'spines' of that kind distally projecting from a large median lobe. Paired labia mostly smooth, inner terminal edge with small field of stiff setae, lacking spines or teeth. Lateral portions of labia locally with knobbly surface similar to that present in anterior portions of carapace. Distal segment of maxillula (Fig. 6F) ending in 10-14 slender, acute, smooth spines; subterminally with 4-6 small, basally barbed setae on caudal face. Mesial margin of endite with dense set of setae, 3-4 of which are strong, extending beyond the distal segment, the latter setae on their distal half barbed by stiff bristles. Maxilla (Fig. 6G-H) with well-developed exopod, 2-segmented palp and four strongly setose endites arising from trunk; exopod elliptical, extending only slightly beyond basal segment of palp, terminally with five plumose setae that decrease in size laterally; 


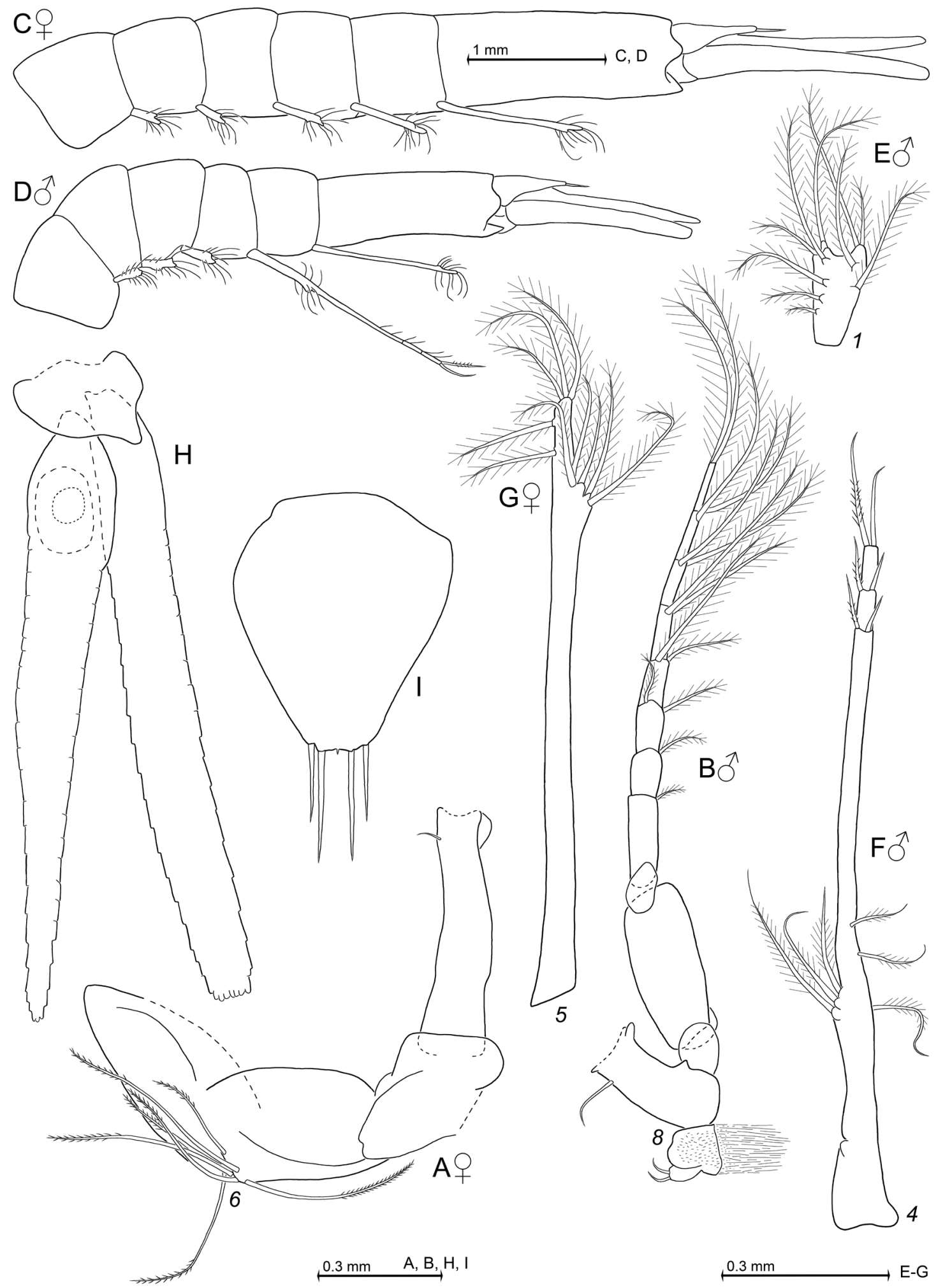

Fig. 7. Abyssomysis cornuta gen. et sp. nov., holotype, adult male with body length $6.6 \mathrm{~mm}$ (D: ZMH 58250), paratypes female $7.9 \mathrm{~mm}$ (A, C, G: ZMH 58256) and males $6.7 \mathrm{~mm}$ (B, F: ZMH 58254), $6.8 \mathrm{~mm}$ (E, H-I: SMF 55190). A. Sixth thoracic sympod with oostegite. B. Eighth thoracic sympod with exopod and penis. C-D. Pleon in female (C) and male (D), lateral. E. First male pleopod. F. Fourth male pleopod. G. Fifth female pleopod. H. Uropods, ventral. I. Telson. 
apical segment of palp is 1.6-1.8 times length of basal segment; terminal margin of apical segment weakly convex, almost truncate, distally with 4-5 modified spine-setae armed with various numbers of spinules and barbs (Fig. 6H); outer edge with a subbasally barbed seta which is longer than the apical segment; inner margin of this segment mostly smooth, with spines and setae only along its distal third, outer margin well setose; first (basal) endite with long, terminally barbed seta overreaching the palp (measured without setae and spines); endites 2-3 each with normal setae plus 3-6 modified setae whose barbs are to varying degree transformed to denticles; endite 4 with smooth or barbed setae only.

Foregut (Fig. 8E-H). Entire foregut with setae and moderately-sized spines only, no clavate spines or heavily armed spines or teeth. Primary cardiac filter formed ventrally by combs of stiff setae at inlet of oesophagus. Cardiac part of foregut with series of short, smooth spines with setae in between, on mesial and terminal margins of lateralia; with slender, microserrated spines (Fig. 8F) on disto-lateral portions of lateralia; and with apically pronged, proximally smooth, slender spines (Fig. 8G) on lateral

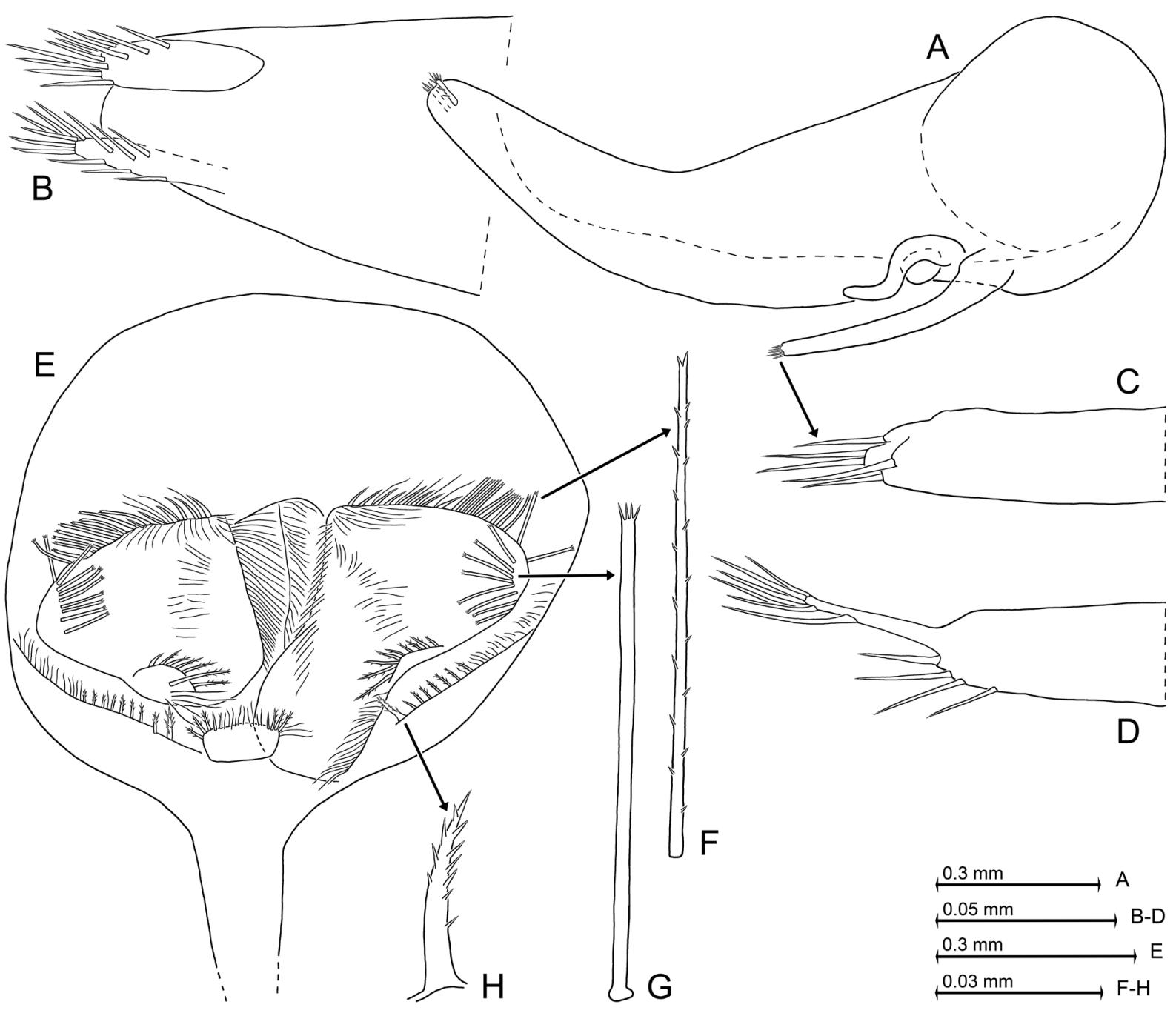

Fig. 8. Abyssomysis cornuta gen. et sp. nov., paratype female with body length $7.9 \mathrm{~mm}$ (E-H: ZMH 58256) and three of its nauplioid larvae at substage N2 (A-D). A. Nauplioid in toto, lateral. B. Tip of nauplioid abdomen in another specimen, obliquely dorsal. C. Detail of panel (A) showing tip of antennula. D. Tip of nauplioid antennula in another specimen. E. Cardiac portion of foregut, dorsal aspect, dorsal wall omitted. F-H. Details of E, showing modified spines. 
portions. Stouter, centro-apically serrated spines (Fig. 8H) of various sizes on posterior part of lateralia, on dorso-lateral infolding, and on disto-lateral edges of superomedianum. Lateralia with weak and superomedianum with even weaker but distinct setation in addition to armature of spines. No setae present in pyloric part of foregut.

THorax (Figs 6I-J, 7A-B). Thoracic exopods 1, 8 with terminally weakly widened basal plate rounded on outer edge. Exopods 2-7 with larger plate that is terminally more strongly widened, its edge more narrowly rounded. Exopods 1, 8 with 8-segmented, exopods 2-7 with 9-segmented, setose flagellum. Endopod 1 (Fig. 6I) only 10-13\% body length measured from basis to dactylus; coxa with $0-3$ setae close to segmental border with basis; basis with long, slender, all along setose endite; remaining segments without endite; dactylus with slender, smooth claw. First thoracic epipod foliaceous, linguiform, without seta. Endopod 2 (Fig. 6J) measures $28-37 \%$ body length; this is more than twice the size of endopod 1; basis with indistinct endite representing a rounded, weak prominence from inner margin; merus of both sexes longer than combined praeischium plus ischium, but shorter than combined carpopropodus plus dactylus; dactylus with brush of setae, without claw. Endopods 3-8 broken. Oostegite 1 (Fig. 7A) comparatively large, contributing to the anterior closure of the marsupium; oostegites 2-3 normal, even larger. Oostegites $1-3$ proximally and dorsally with setae bearing short, acute barbs along distal $30-50 \%$; ventral margin of oostegites 2-3 with plumose setae covering the slit between opposite, homologous oostegites. Penes (Fig. 7B) short, apically bilobate, with two large (related to penis size), smooth setae. No median processes visible on sternites $4-8$ of both sexes.

Pleon (Fig. 7C-I). Sixth pleomere $1 / 5-1 / 6$ body length. Width of pleopods, uropods and telson perspectively narrowed in Fig. 7C, D. Pleopod 4, when stretched posteriorly, reaches (without setae) to distal third of pleonite 5 in females, almost to the end of that pleonite in males. Tip of male pleopod 4 (Fig. 7F) with one smooth seta and one slightly longer, medially barbed seta. The smooth seta shorter up to about as long as the combined two apical segments. The median and the basal segments also end in a pair of such setae, but with both setae shorter and the smooth one more robust. The long basal segment subterminally with 0-2 additional, smooth, robust setae; additional 6-9 longer, barbed setae at $1 / 3$ segment length from basis.

ENDOPOD OF UROPODS (Fig. 7H) with comparatively small statocyst containing a small statolith mineralized with fluorite; statoliths spherical in dorsal view, diameter $71-89 \mu \mathrm{m}$, this is $1.0-1.2 \%$ body length ( $\mathrm{n}=10$ statoliths of 5 adults). Statolith formula not well established. Terminal margin of telson (Fig. 7I) with or without a minute median tooth. The inner robust spines of telson measure $41-45 \%$ telson length, the outer ones $31-37 \%$.

\section{Distribution}

Recorded at stations \#344, \#348 and \#350 in the abyssal plain of the Angola Basin, range $16^{\circ} 13^{\prime} \mathrm{S}$ to $16^{\circ} 17^{\prime} \mathrm{S}, 4^{\circ} 40^{\prime} \mathrm{E}$ to $5^{\circ} 27^{\prime} \mathrm{E}$, depth $5430-5460 \mathrm{~m}$ (Table 1). All positive samples were taken with selfclosing epibenthic sledge. At least one sample was captured in the lower, another one in the upper net, suggesting that at least some specimens were positioned shortly above the sediment.

\section{Eggs and larvae}

Considering only non-damaged specimens, the female with $8.0 \mathrm{~mm}$ body length carried eight eggs with diameters of $0.47-0.50 \mathrm{~mm}$, the female with $7.9 \mathrm{~mm}$ carried six nauplioid larvae at substage $\mathrm{N} 2$ with 1.3-1.5 mm body length. Nauplioids (Fig. 8A-D) with smooth cuticle all around, except for 5-10 slender spines at tip of antennula and a pair of cercopods in subapical position on abdomen. Each cercopod armed with a fan of numerous acute, slender spines. 


\section{Gut contents}

Two dissected foreguts contained mainly fine, unidentifiable material, mineral particles and fragments of detritus; maximum size of particles $12 \mu \mathrm{m}$. These components also found in midgut and hindgut, with greater fraction of mineral particles also in oesophagus. There were no traces of meiofauna or macrofauna in oesophagus and foregut.

\section{Discussion}

\section{Horizontal distribution}

The three species of Lophogastrida and one species of Mysida collected by "DIVA-1" in the Angola Basin show panoceanic or circumtropical distribution, respectively, with roughly symmetrical latitudinal limits: $66^{\circ} \mathrm{N}-74^{\circ} \mathrm{S}$ in Neognathophausia gigas, $66^{\circ} \mathrm{N}-64^{\circ} \mathrm{S}$ in Eucopia grimaldii, $45^{\circ} \mathrm{N}-40^{\circ} \mathrm{S}$ in Siriella thompsonii, and $34^{\circ} \mathrm{N}-22^{\circ} \mathrm{S}$ in Fagegnathophausia gracilis. The new record at $22^{\circ} \mathrm{S}$ made the latitudinal limits of the latter species roughly symmetrical. The limits of $51^{\circ} \mathrm{N}-54^{\circ} \mathrm{S}$ are also symmetrical in the Mysida species Boreomysis bispinosa but confined to the Atlantic Ocean including the Atlantic sector of the Southern Ocean.

Four of the Mysida species reported here have previously been known only from the Northern Hemisphere. Their latitudinal range is now extended southward to the Angola Basin in the SE-Atlantic. The resulting limits are $60^{\circ} \mathrm{N}-22^{\circ} \mathrm{S}$ in the E-Atlantic for Amblyops tenuicauda, $61^{\circ} \mathrm{N}-22^{\circ} \mathrm{S}$ in the E-Atlantic and Mediterranean for Paramblyops rostratus, $62^{\circ} \mathrm{N}-17^{\circ} \mathrm{S}$ in the E-Atlantic and Mediterranean for Pseudomma nanum, and $58^{\circ} \mathrm{N}-22^{\circ} \mathrm{S}$ in the E-Atlantic, W-Mediterranean and NW-Pacific (off Japan) for Parapseudomma calloplura. The data for the here first-described species from the Angola Basin are $20^{\circ} \mathrm{S}$ for Petalophthalmus cristatus, $16-17^{\circ} \mathrm{S}$ for Abyssomysis cornuta gen. et sp. nov.

Among the five here listed, non-panoceanic Mysida species from the N-Atlantic, only Boreomysis bispinosa has also been previously reported from the S-Atlantic. The new southern limits encountered in the Angola Basin are in line with the conclusions by Brandt et al. (2005) that the abyssal isopod fauna of the Angola Basin appears to be isolated from the subantarctic and South African deep fauna; and that the Walvis Ridge may represent a main distribution barrier for the abyssobenthos in the south of the Angola Basin.

The epibenthic sledge samples yielded smaller numbers of abyssobenthic Mysida species in the southern study area no. 1 compared to the northern areas 5-6 (Table 1). However, the numbers of positive stations and species were insufficient to test the significance of that pattern. Based on relatively abundant peracarid taxa - mostly isopods and cumaceans (but only a few mysids) - Brandt et al. (2005) found significantly lower species diversity in the southernmost station compared to the northern stations. They argued that the difference may reflect higher food concentrations as concluded from higher biomass and taxa numbers recorded by Kröncke \& Türkay (2003) in box corer samples at the more northern stations. According to the latter authors the different yields appear to be related to different water masses north and south of the Angola-Benguela Front crossing the study area, whereby the production in the north appears favoured by the input of nutrients and suspended matter from rivers.

In analogy, the "Valdivia" expedition yielded in the Gulf of Guinea a higher diversity of Lophogastrida and Mysida with vertical hauls from 600-4000 m depth to the surface in the northern, warmer waters of the Guinea Current compared with hauls from 3000-4000 $\mathrm{m}$ to the surface in the more southern, colder waters of the Benguela Current (see yields in samples listed by Illig 1930: 485-486; species list supplemented by Wittmann in press). 


\section{Vertical distribution}

The circumtropical lophogastrid Fagegnathophausia gracilis is essentially bathypelagic, previously known from a depth range of 500-5225 m. The panoceanic Neognathophausia gigas is meso- to bathypelagic, range 650-4023 m; Eucopia grimaldii is also essentially meso- to bathypelagic, range 200-4829 m. The bottom depths, 5161-5430 m, of the new samples in the Angola Basin are mostly greater than the previously published limits, but the actual sampling depths may have been shallower due to the use of a non-closing device (Agassiz Trawl). All five Lophogastrida species sampled by the combined "Valdivia" and "DIVA-1" expeditions in waters of the Angola Basin show a circumtropical to panoceanic distribution and are essentially meso- to bathypelagic; none are epipelagic.

In the Angola Basin the normally epipelagic Mysida species Siriella thompsonii was sampled with the Bongo net at the surface, while one juvenile specimen was taken with the box corer at $5493 \mathrm{~m}$ bottom depth. Catching this species with a box corer sounds unlikely but has its precedence in a single specimen recorded by Price et al. (1986) in a daytime grab sample from $46 \mathrm{~m}$ depth in the Gulf of Mexico. The precise sampling depth cannot be judged for Petalophthalmus cristatus taken at or over $5487-5497 \mathrm{~m}$ bottom depth in the Angola Basin because it was captured with a non-closing device (Agassiz Trawl).

The remaining six Mysida species in the present collection were taken on and a short distance above the sea floor of the Angola Basin with a self-closing epibenthic sledge that gives reliable information on sampling depth. Among these all five previously described species were known only from less than $5000 \mathrm{~m}$ depth. Depth limits of the present samples are integrated with published limits, yielding the following new ranges: 700-5460 m in Boreomysis bispinosa, 450-5433 m in Amblyops tenuicauda, 200-5434 $\mathrm{m}$ in Paramblyops rostratus, 360-5460 m in Pseudomma nanum, and $94-5460 \mathrm{~m}$ in Parapseudomma calloplura. The range is $5430-5460 \mathrm{~m}$ in the here first described Abyssomysis cornuta gen. et sp. nov.

Among the species taken with epibenthic sledge, Pseudomma nanum was present only in the epinet, despite the fact that this species was considered suprabenthic by Madurell \& Cartes (2003). Boreomysis bispinosa, Amblyops tenuicauda, Paramblyops rostratus, Parapseudomma calloplura and Abyssomysis cornuta gen. et sp. nov. appeared in both epinet as well as supranet, pointing at least partly to a suprabenthic habit. In accordance with this, $B$. bispinosa has already previously been taken with both benthic and pelagic devices. Sorbe \& Elizalde (2013) considered Paramblyops rostratus as suprabenthic. Frutos \& Sorbe (2013) sampled Parapseudomma calloplura in the near-bottom water layer.

All seven Mysida species (listed in the Introduction) sampled by the "Valdivia" expedition in waters of the Angola Basin show a circumtropical to panoceanic distribution. Among these species six are essentially meso- to bathypelagic, only Arachnomysis megalops is mesopelagic, and none are epipelagic. These seven species were not found in the "DIVA-1" material, most likely due to greater sampling depth and exclusion of pelagic species by the prevailing use of devices that keep the nets open only during contact with the sea floor.

\section{Feeding and deep-sea adaptation}

The weak grinding surface of the processus molaris in both mandibles, the reduced lacinia mobilis in the right mandible and the absence of large, heavily armed spines or teeth in the foregut (Fig. 8E-H) suggest weak abilities of Abyssomysis cornuta gen. et sp. nov. for macerating large and/or hard particles. The second thoracic endopod has no claw, but resembles a brush with a long, slender broomstick. These features point to sweeping for soft food rather than predation. Finely particulate organic material together with minute mineral particles in the foregut (examined in two specimens) confirm that the mouth-parts are used for sweeping detritus from the sediment surface. The absence of the secondary filter also favours infiltration of mineral particles from the foregut into the midgut. The maximum particle size of 
$12 \mu \mathrm{m}$ in the foregut fits with sediment parameters in the study area, where Kröncke \& Türkay (2003) obtained $95-99 \%$ of the sediment samples by passing through a sieve with $63 \mu \mathrm{m}$ mesh size. As a striking analogy, the masticatory part with lacinia mobilis absent in the right mandible of Mysimenzies hadalis Băcescu, 1971 (tribe Mysimenziesini) shows an astounding similarity, almost identical with that found in A. cornuta gen. et sp. nov. females. Details about feeding are not known in the former species.

Reduction of the lacinia mobilis on one of the two mandibles is also found in at least nine bathyal to abyssal species of the genera Hansenomysis Stebbing, 1893, Bacescomysis Murano \& Krygier, 1985, Petalophthalmus and Ipirophthalmus gen. nov. These three genera belong to the Petalophthalmidae and are morphologically remote from Abyssomysis gen. nov. and Mysimenzies Băcescu, 1971. In the respective species of Petalophthalmidae, the lacinia mobilis of the left or the right mandible is reduced to varying degrees (Birstein \& Tchindonova 1958; Băcescu 1971a, 1971b; De Jong-Moreau et al. 2001; San Vicente \& Corbari 2015; present study). Based on the strong setation of perioral structures Băcescu (1971b) argued that Hansenomysis species are detritus feeders. This was confirmed by SEM-studies that De Jong-Moreau et al. (2001) performed on the processus molaris in Bacescomysis abyssalis Murano \& Krygier, 1985, a species closely related to Hansenomysis. They found a smoother and more concave processus compared to that in omnivorous Mysida from bathyal to sublittoral environments, which show a phytophagous and carnivorous tendency.

The feeding type is less clear for the above-described Petalophthalmus cristatus sp. nov. because it has a trilobate processus molaris with a weaker setation in the right mandible. The broom-like thoracic endopod 5 may hint at detritus feeding. In line with this, the spines of the gastric mill are small in relation to the size of the foregut (Fig. 4A-E). The numbers and absolute sizes of the spines are not larger than those found in much smaller sized, sublittoral species of the family Mysidae, many of which show a predatory mode of life (e.g., three species of Mysidopsis G.O. Sars, 1864, studied by Wittmann \& Griffiths 2018). At the same time, the prehensile, heavily armed thoracic endopods 1-2 (found in all species of Hansenomysis, Petalophthalmus and Ipirophthalmus gen. nov.) and the giant mandibular palps (in Petalophthalmus and Ipirophthalmus gen. nov.) are indicative of a predatory habit. As a possible synthesis of the divergent characteristics, P. cristatus sp. nov. may be omnivorous, probably advantageous for survival in oligotrophic, deep oceanic waters.

As an additional, striking analogy of Abyssomysis cornuta gen. et sp. nov. with species of Petalophthalmidae, all seven currently acknowledged bathyal to abyssal species of Bacescomysis and seven species of Hansenomysis show a non-incised, transverse eyeplate with well-developed horn-like extensions lacking visual elements. The remaining eleven species of Hansenomysis exhibit rounded, lappet-like or inconspicuous extensions (Faxon 1895; Băcescu 1971b; Lagardère 1983; Murano \& Krygier 1985; Bravo \& Murano 1997b; Casanova \& de Jong 2005; San Vicente \& Sorbe 2008). Due to the lack of visible sensory structures the horns and lappets are here interpreted as remnants of convergent eye reduction in dark, deep waters. This is also valid for the larger eyes with reduced cornea in the here revised genus Petalophthalmus.

\section{Morphology of the Petalophthalminae and establishment of Ipirophthalmus gen. nov.}

Only five species today, considered valid, have been described between 1875 and 1998 as pertaining to the genus Petalophthalmus. This contrasts with as many as three additional species, including the new one, in the period 2014-2020. The recent increase to a total of eight species has highlighted a previously unnoticed morphological divergence within this genus. This first group includes the type species $P$. armiger together with P. papilloculatus, $P$. papuaensis and $P$. cristatus sp. nov., characterized by reduced eyes, anterior carapace margin without pair of distinct submedian processes, and terminal margin of the telson with spines but without setae. The second group comprises P. liui, P. macrops, $P$. oculatus and P. caribbeanus with well-developed, functional cornea, anterior carapace margin with 
a pair of submedian processes flanking the rostrum, and terminal margin of the telson with setae and spines. The latter set of characters is shared with both so far known species of Pseudopetalophthalmus, suggesting an inconsistency between the former morphological concepts of Petalophthalmus and Pseudopetalophthalmus. In order to eliminate this supposed inconsistency (polyphyly) of the two character sets within the genus Petalophthalmus, the species P. liui, P. macrops, P. oculatus and $P$. caribbeanus are transferred to a separate genus, here named Ipirophthalmus gen. nov. The redefined Petalophthalmus and the new Ipirophthalmus gen. nov. share an antennal scale that is setose all around, differing by that feature from the remaining two genera of the subfamily Petalophthalminae, namely from Pseudopetalophthalmus and Parapetalophthalmus characterized by a smooth outer portion of the antennal scale ending at a single spine.

The type species Ipirophthalmus liui and I. macrops along with all four now known species of Petalophthalmus share thoracic endopods 3-4 reduced to only 1-2 segments, and endopod 5 elongate, ending in a brush of setae (Fig. 3C). These legs were reported as being different in the remaining two species here also assigned to Ipirophthalmus gen. nov.: Pillai (1968) reported an elongate endopod 4 ending in a brush of setae upon redescription of P. oculatus (now I. oculatus) based on a single specimen. San Vicente \& Corbari (2015), however, concluded that Pillai (1968) may have confounded endopod 5 with endopod 4, due to the habitus of this specimen illustrated by Pillai (1968: fig. 1) with thoracopods 3-4 broken. Upon first description of P. caribbeanus (now I. caribbeanus), O.S. Tattersall (1968) noted without presentation of figures: "Third thoracic appendage long and very slender with the distal end armed with a cluster of setae surrounding a very minute nail". According to Lagardère (1983) and Fukuoka (2009), any (up to all) of the endopods 3-5 ending in a brush are also found in a number of species of Hansenomysis Stebbing, 1893, Ceratomysis Faxon, 1893 and Bacescomysis Murano \& Krygier, 1985, all belonging to the subfamily Hansenomysinae Wittmann, Ariani \& Lagardère, 2014, within the family Petalophthalmidae. That type of endopod was so far reported from diverse species in five out of a total of seven genera; this wide distribution suggests symplesiomorphy for both subfamilies of the Petalophthalmidae.

\section{Validity of Petalophthalmus cristatus sp. nov.}

The new species fits perfectly with the above-revised diagnosis of the genus Petalophthalmus. Accordingly, its validity requires a detailed discussion solely of the differences from the remaining three species of its genus:

The characters reported by Hendrickx \& Hernández-Payán (2018) upon redescription of Petalophthalmus armiger Willemoës-Suhm, 1875 differ from the new species in the outer flagellum of antennular peduncle without subbasal ridge; antennal flagellum of female figured by these authors with more ( $>11$ ) segments; merus of thoracic endopod 2 with outer margin smooth, carpopropodus with only three setae on outer margin; flagellum of thoracic exopods 3-4 with more segments (19-21); endopod 5 with subequal praeischium, ischium and merus (vs much longer merus in Fig. 3C), carpus not shorter than propodus; female pleopods terminally without pair of spines (vs present in Fig. 3O-P); basal segment of uropodal exopod without basally barbed seta (in addition to spines) on disto-lateral corner.

Petalophthalmus papilloculatus San Vicente, Frutos \& Cartes, 2014 differs, according to its first description, from the new species by a small, acute tooth behind anterior margin of carapace, no rostrum developed; outer flagellum of antennular peduncle without subbasal ridge; antennal flagellum with fewer (5) segments in females; pars centralis of right mandible without digitus; distal segment of maxillula with few (7) serrated spines; claw of thoracic endopods 1-2 fused with dactylus; coxa of endopod 1 without endite; merus of endopod 2 with smooth outer margin, carpopropodus without barbed setae apart from the usual smooth setae; flagellum of exopods 3-4 with more segments (19-20); 
endopod 8 shorter than exopod; endopod of uropods not extending beyond telson; basal segment of exopod with three spines but no barbed seta on disto-lateral corner.

Petalophthalmus papuaensis San Vicente \& Corbari, 2015, differs according to its first description, from the new species by the presence of some scattered visual elements in the globular cornea; small, acute tooth behind anterior margin of carapace, no rostrum developed; outer flagellum of antennula without subbasal ridge; antennal flagellum of female with more (7) segments; processus molaris of right mandible not trilobate; distal segment of maxillula with fewer (7) serrated spines; coxa of thoracic endopod 1 without endite; carpopropodus of endopod 2 without barbed setae apart from the usual smooth setae; endopod 5 without apical claw, terminal margin of propodus armed with two short cuspidate setae in addition to the pair of microserrated setae, the latter as in Fig. 3D; flagellum of thoracic exopods with few segments: exopods $3-4$ with $13-15$, exopod 5 with 16 , exopods $6-8$ with $13-16$; female pleopod 1 unsegmented; female pleopods 1-4 (possibly also no. 5) terminally without pair of spines as in Fig. 3OP; basal segment of uropodal exopod with three spines but no barbed seta on disto-lateral corner.

\section{Historical outline of the tribe Calyptommini W.M. Tattersall, 1909}

Based on the undivided eyeplate and the rod-like pleopods 1-5 in both sexes, W.M. Tattersall (1909) established the subfamily Calyptomminae as a monotypic taxon upon first description of Calyptomma puritani W.M. Tattersall, 1909. Hansen (1910) did not list this subfamily in his key to subfamilies and tribes of the Mysidae. Shortly thereafter, W.M. Tattersall (1911) redefined the Calyptomminae in order to receive the most similar genus Michthyops W.M. Tattersall, 1911, newly established by him for two species previously attributed to the genus Pseudomma G.O. Sars, 1870, by Vanhöffen (1897) and Ohlin (1901). Without indication of details, Illig (1930) and Tchindonova (1981) listed Calyptomma and Michthyops within the tribe Erythropini, whereas Mauchline (1980) placed Calyptomma within the Leptomysini but Michthyops within the Erythropini. Finally, Nouvel et al. (1999) reinstituted the Calyptomminae at tribe level as Calyptommini and followed W.M. Tattersall (1911) by inclusion of Calyptomma as well as Michthyops. A close relationship of the two genera was confirmed with sequencing of nuclear small-subunit ribosomal DNA by Meland \& Willassen (2007) and Chevaldonné et al. (2015), who equally obtained Michthyops parva (Vanhöffen, 1897) (now as M. parvus) and Calyptomma sp. as closely-related species within the subfamily Erythropinae. The reinstitution proposed by Nouvel et al. (1999) was acknowledged by Wittmann et al. (2014), Meland et al. (2015) and San Vicente (2017). In accordance with the resulting system, Wittmann et al. (2014) provided revised diagnoses of the tribes Erythropini and Calyptommini, the latter now revised further as explained below.

\section{Monotypy, validity and affiliation of Abyssomysis cornuta gen. et sp. nov.}

The sexual dimorphism among the ten specimens studied here goes beyond published data for most species in the order Mysida. Unusual dimorphisms of the new species are the structure and relative dimensions of the antennal peduncle, lacinia mobilis, and by the setation of the mandibular palpus. Importantly, mandible structure has so far been poorly checked for dimorphisms, and the mandibles are particularly scantly known in the tribe Calyptommini. Be that as it may, the strong differences pose the question whether the five females and five males studied here may represent more than a single species. Arguments for monotypy are supported by the fact that both sexes were found together at three stations, no other specimens were found elsewhere, and based on the detailed structure of eyeplate, maxillula, maxilla, first and second thoracic endopods, and telson.

Within the Erythropinae the new genus and species fits with the tribe Calyptommini W.M. Tattersall, 1909, by eyeplate without median cleft, by uniramous pleopods, reduced to endopods in both sexes, unsegmented in female pleopods $1-5$ and male pleopods $1-3,5$, and by non-serrated lateral margins of the telson. However, it differs from all four so far known species of this tribe by rudimentary eyestalks laterally on the eyeplate and by segmentation of the uniramous male pleopod 4. 
Uniramous pleopods reduced to unsegmented endopods in both sexes (with the exception of the segmented [uniramous] fourth male pleopod) are shared by the new taxon with Inusitatomysis insolita Ii, 1940, the only representative of the tribe Inusitatomysini Wittmann, Ariani \& Lagardére, 2014. However, this species differs strongly by well-developed eyes, serrated outer margin of the antennal scale, and a pair of setae arising from the bottom of the telson cleft.

Rudimentary eyestalks laterally on the eyeplate are shared by the new taxon with Marumomysis hakuhoae Murano, 1999, and M. antarctica San Vicente, 2007, pertaining to the tribe Mysimenziesini Tchindonova, 1981. However, the Mysimenziesini differ from the new taxon by the basal segment of the antennular trunk medio-dorsally with sensory fossette or with setose elevation, by a biramous fourth male pleopod with both rami multi-segmented, and by serrated lateral margins of the telson.

According to the diagnoses by Wittmann et al. (2014), all remaining tribes of the Erythropinae show welldeveloped, biramous male pleopods, with the reservation that males are unknown in the Thalassomysini Nouvel, 1942. This tribe is remote from the new taxon by well-developed, separate eyestalks with a cornea reduced to different degrees, an antennal scale setose all around, a strongly asymmetrical labrum, and four pairs of oostegites.

In summary, Abyssomysis cornuta gen. et sp. nov. differs from all remaining taxa of Erythropinae and even from all Mysida by the combination of rudimentary eyestalks laterally on the eyeplate together with uniramous pleopods reduced to unsegmented endopods in both sexes, with the exception of the segmented (uniramous, endopodal) fourth male pleopod. The overall morphological distance appears least from the Calyptommini, whose diagnosis is consequently here amended to cover the respective combination of characters found in the new genus and species.

\section{Key to genera and species of the subfamily Petalophthalminae}

Distribution data modified and updated from San Vicente et al. (2014).

Petalophthalmidae with mandibular palp long, powerful, and prehensile; thoracopods 1-2 without exopod, thoracopods 3-8 with well-developed exopods; powerful subchelae formed by thoracic endopods 1-2; merus of endopod 1 with large endite; ischium of endopod 2 with again larger, subquadrangular endite; endopod 5 normal-sized or elongate; endopods 3-4, 6-8 normal or reduced to different degrees; female pleopods uniramous or biramous, male pleopods biramous; exopods of uropods with subterminal suture. Subfamily Petalophthalminae Czerniavsky, 1882 (panoceanic, depth 0-5500 m, mainly $100-500 \mathrm{~m}$ )

1. Outer margin of antennal scale with smooth portion ending at a single spine; eyes well

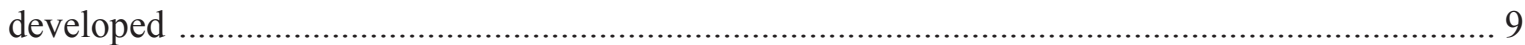

- Antennal scale setose all around; cornea well developed or reduced ............................................. 2

2. Eyes without or with strongly reduced visual elements; terminal margin of telson without setae, with spines and in most species also with small teeth. Genus Petalophthalmus Willemoës-Suhm, 1874.

- Cornea well developed, functional; terminal margin of telson with setae, spines, and with small teeth in between. Ipirophthalmus gen. nov.

3. Antennal scale 2-segmented; disto-lateral corner of the basal segment of the exopod of uropods with spines only, without seta; coxa of thoracic endopod 1 without endite

Ipirophthalmus liui (Wang, 1998) gen. et comb. nov. (northern South China Sea, depth 194-219 m)

- Antennal scale unsegmented; disto-lateral corner of the basal segment of the exopod of uropods with several spines and one seta; coxa of thoracic endopod 1 with endite 
4. Telson mid-terminally emarginated by, if at all, up to $1 \%$ of its length, lateral margins with 21-22 spines each, terminal margin with two long setae, nine large, toothed spines and small teeth in between Ipirophthalmus macrops (Tchindonova \& Vereshchaka, 1991) gen. et comb. nov. (W-Indian Ocean: off Madagascar, benthopelagic, depth 360-555 m)

- Telson mid-terminally emarginated by, if at all, up to 5\% of its length, lateral margins with less than 20 spines each, terminal margin with four long setae, seven large, toothed spines and small teeth in between

5. Telson mid-terminally emarginated by about $5 \%$ of its length, lateral margins with $12-15$ spines each; eyestalk without ocular papilla; female pleopods biramous caribbeanus (O.S. Tattersall, 1968) gen. et comb. nov. (Caribbean, mesopelagic, depth 329-366 m)

- Telson mid-terminally emarginated by about $2 \%$ of its length; lateral margins with 17-18 spines each; eyestalk with ocular papilla; female pleopods uniramous

Ipirophthalmus oculatus (Illig, 1906) gen. et comb. nov. (NW-Arabian Sea, W-Indian Ocean, off Japan, mesopelagic to bathybenthic, depth $\leq 1200 \mathrm{~m}$ according to Illig 1906, compatible with 220-430 m indicated by San Vicente et al. 2014)

6. Anterior margin of carapace truncate, without rostrum; eyes without or with some small, scattered visual elements

- Anterior margin of carapace with triangular rostrum forming a longitudinal crista; eyes without visual elements

7. Eyes leaf-like; merus of thoracic endopod 2 with outer margin smooth, carpopropodus with three short setae on outer margin; thoracic endopod 5 with subequal praeischium, ischium and merus; carpus not shorter than propodus Petalophthalmus armiger WillemoësSuhm, 1875 (panoceanic, $56^{\circ} \mathrm{N}$ to $46^{\circ} \mathrm{S}$, bathypelagic to abyssobenthic, depth 900-4572 $\mathrm{m}$ )

- Eyes elongate ovoid, dorsoventrally flattened by a factor of 1.4; merus of thoracic endopod 2 with five large setae on outer margin, carpopropodus with three long and six short setae on outer margin; merus of thoracic endopod 5 longer than combined praeischium and ischium; carpus less than half length of propodus

Petalophthalmus cristatus sp. nov. (SE-Atlantic: Angola Basin, depth $\leq 5497 \mathrm{~m}$ )

8. Eyes without eyestalks and without visual elements. Merus of thoracic endopod 2 with outer margin smooth, carpopropodus with three setae on outer margin; thoracic endopod 5 with subequal ischium, merus and carpus, each longer than praeischium, propodus 2 -segmented with proximal segment half length of the distal one; telson with 25-37 spines on distal $2 / 3$ of each lateral margin

Petalophthalmus papilloculatus San Vicente, Frutos \& Cartes, 2014 (NE-Atlantic: Galicia Bank off Iberian Peninsula, depth 1536-1809 m)

- Eyes with definite eyestalks, globular cornea containing some scattered visual elements not forming a compound sensory organ; merus of thoracic endopod 2 with outer margin bearing seven setae, carpopropodus with three long and six short setae along outer margin; endopod 5 with subequal praeischium, ischium and merus, carpus $2 / 3$ length of propodus; telson with $20-22$ spines on distal half of each lateral margin

Petalophthalmus papuaensis San Vicente \& Corbari, 2015 (tropical W-Pacific: Bismarck Sea, depth 800-1065 m)

9. Thoracic endopods 6-8 rudimentary, with only $1-2$ segments; thoracic endopods $3-4$ terminating in two setae ...................................monotypic genus Parapetalophthalmus Murano \& Bravo, 1998; species P. suluensis Murano \& Bravo, 1998 (central Indo-Pacific: Sulu Sea, depth 285-306 m) - Thoracic endopods 3-8 with more than four segments terminating in strong claw. Genus Pseudopetalophthalmus Bravo \& Murano, 1997 
10. Claw of thoracic endopods 1-2 fused with dactylus; thoracic endopods 3-5 with carpopropodus longer than merus; lateral margins of telson with four spines

Pseudopetalophthalmus australis (Panampunnayil, 1982) (west coast of Australia, nocturnal surface to subsurface plankton)

- Claw of thoracic endopods 1-2 not fused with dactylus; thoracic endopods 3-5 with carpopropodus shorter than merus; lateral margins of telson with 7-8 spines

Pseudopetalophthalmus japonicus Bravo \& Murano, 1997 (east coast of central Japan, epibenthic, depth 74-130 m)

\section{Key to genera and species of the tribe Calyptommini}

Distribution data modified and updated from Petryashov (2014).

Mysidae: Erythropinae with eyeplate showing no distinct median cleft, plate mainly formed by a transverse median bridge, eyes rudimentary or absent. Smooth outer margin of antennal scale ending in a tooth. Pleopods uniramous, reduced to sparsely setose rods or plates in both sexes. Telson entire, its lateral margins mostly smooth, terminal portions with spines Tribus Calyptommini W.M. Tattersall, 1909 (Arctic and Atlantic oceans, Mediterranean, $81^{\circ} \mathrm{N}$ to $17^{\circ} \mathrm{S}$, depth $27-5460$ m, mainly bathybenthic)

1. Lateral portions of eyeplate with anteriorly directed, conical lobes; telson about as long as wide; appendix masculina strong, with large brush of setae

......Abyssomysis cornuta gen. et sp. nov. (abyssal plain of the Angola Basin, depth 5430-5460 m)

- Eyeplate without antero-lateral protrusions; telson length at least twice the width at basis; appendix masculina reduced, without brush of setae

2. Anterior margin of eyeplate in the middle with a deep, rounded depression; antennal scale short, not extending beyond antennular trunk; telson subtriangular, terminally rounded ............................................................. monotypic genus Calyptomma W.M. Tattersall, 1909, with species Calyptomma puritani W.M. Tattersall, 1909 (Mediterranean, depth 600-1860 m)

- Anterior margin of eyeplate without or with a very small median depression; antennal scale clearly extending beyond antennular trunk; telson trapezoid, terminally rounded. Genus Michthyops W.M. Tattersall, 1911

3. Eyeplate completely or for the most part covered by flattened anterior edge of carapace; length of antennal scale exceeds seven times width; terminal margin of telson with 3-4 pairs of robust spines

Michthyops

arcticus Petryashov, 1993 (Arctic: Canadian basin, north of Laptev Sea, depth 1079-3550 m)

- Eyeplate covered by anterior edge of carapace for less than half its length; length of antennal scale less than seven times width

4. Telson length less than 2.5 times maximum width near basis; terminal margin of telson with three pairs of robust spines

Michthyops parvus (Vanhöffen, 1897) (N-Atlantic, Arctic, depth 183-2900 m)

- Telson length exceeds 2.5 times maximum width near basis; terminal margin of telson with 4-8 (mostly 5-6) pairs of robust spines

Michthyops theeli (Ohlin, 1901) (Circumarctic, Greenland Sea, depth 27-2245 m)

\section{Acknowledgements}

The author is greatly indebted to Ute Muehlenhardt-Siegel from the Zoological Museum Hamburg for loan of material and bibliographic data about the "Meteor" expeditions, particularly also for the great patience with the long-lasting loan and examinations. 


\section{References}

Ariani A.P. \& Wittmann K.J. 2005. Crustacea Malacostraca I. Mysidacea. In: Relini G. (ed.) La Checklist della Fauna Marina Italiana fasc. 29. S.I.B.M. Società Italiana di Biologia Marina, Roma. Available from http://www.sibm.it/CHECKLIST/29\%20CRUSTACEA\%20 MALACOSTRACA\%20I/Mysidacea/Mysidacea.htm [accessed 15 Feb. 2007]

Astthorsson O.S. 1987. Records of Eucopia grimaldii, Hansenomysis fyllae, Hemimysis lamornae, and Mysis litoralis (Mysidacea) from Icelandic waters. Sarsia 72 (1): 37-39. https://doi.org/10.1080/00364827.1987.10419703

Băcescu M. 1941. Les Mysidacés des eaux méditerranéennes de la France (spécialement de Banyuls) et des eaux de Monaco. Bulletin de l'Institut océanographique de Monaco 795: 1-46.

Băcescu M. 1971a. Mysimenzies hadalis g.n. sp.n., a benthic mysid of the Peru Trench, found during cruise XI/1965 of R/V Anton Bruun (U.S.A.). Revue roumaine de Biologie - Zoologie 16 (1): 3-8.

Băcescu M. 1971b. Contributions to the Mysid Crustacea from the Peru-Chile Trench (Pacific Ocean). In: Scientific Results of the Southeast Pacific Expedition. Anton Bruun Report 7: 3-24.

Băcescu M. 1989. Contributions à l'étude du genre Erythrops (Crustacea, Mysidacea) du voisinage du Detroit de Gibraltar. Travaux du Muséum d'Histoire naturelle «Grigore Antipa» 30: 119-127.

Balzer W., Alheit J., Emeis K.C., Lass H.U. \& Türkay M. 2006. South-East Atlantic 2000, Leg M48/1; Cruise No. 48, 6 July 2000 - 3 November 2000, Walvis Bay - Walvis Bay. Meteor-Berichte 06-5 (chapters 1-5). https://doi.org/10.2312/cr_m48

Birstein J.A. \& Tchindonova Yu.G. 1958. The deep sea mysids of the northwest Pacific Ocean. Trudy Instituta Okeanologii Akademii Nauk SSSR 27: 258-355.

Brandt A., Brenke N., Andres H.-G., Brix S., Guerrero-Kommritz K., Mühlenhardt-Siegel U. \& Wägele J.-W. 2005. Diversity of peracarid crustaceans (Malacostraca) from the abyssal plain of the Angola Basin. In: Kröncke I. \& Türkay M. (eds) Results of the DIVA-1 Expedition of RV “Meteor" (Cruise M48/1). Organisms Diversity \& Evolution 5 (Suppl. 1): 105-112.

Brandt A., Brenke N., Mühlenhardt-Siegel U. \& Wägele J.W. 2006. 1. 4. 6 Macrofauna represented in sledge-samples. In: Balzer W., Alheit J., Emeis K.C., Lass H.U. \& Türkay M. (eds) South-East Atlantic 2000, Leg M48/1; Cruise No. 48, 6 July 2000 - 3 November 2000, Walvis Bay - Walvis Bay. MeteorBerichte 06-5: 1-22 to 1-26. https://doi.org/10.2312/cr_m48

Bravo M.R. \& Murano M. 1997a. Pseudopetalophthalmus japonicus, new genus, new species (Mysidacea: Petalophthalmidae). Journal of Crustacean Biology 17 (4): 725-732.

https://doi.org/10.1163/193724097X00152

Bravo M.R. \& Murano M. 1997b. New records of the genus Hansenomysis in Japan with description of a new species (Crustacea: Mysidacea: Petalophthalmidae). Proceedings of the Biological Society of Washington 110 (2): 227-235.

Burnham R.E. 2015. Reproductive strategies conferring species dominance in marine mysid (Peracarida, Mysida) species in coastal waters off Vancouver Island, BC. Crustaceana 88 (12-14): 1421-1438. https://doi.org/10.1163/15685403-00003502

Cartes J.E. \& Sorbe J.-C. 1995. Deep-water mysids of the Catalan Sea: species composition, bathymetric and near-bottom distribution. Journal of the Marine Biological Association of the United Kingdom 75 (1): 187-197. https://doi.org/10.1017/S0025315400015290 
Cartes J.E., Jaume D. \& Madurell T. 2003. Local changes in the composition and community structure of suprabenthic peracarid crustaceans on the bathyal Mediterranean: influence of environmental factors. Marine Biology 143: 745-758. https://doi.org/10.1007/s00227-003-1090-z

Cartes J.E., Maynou F., Moranta J., Massut E., Lloris D. \& Morales-Nin B. 2004. Patterns of bathymetric distribution among deep-sea fauna at local spatial scale: comparison of mainland vs. insular areas. Progress in Oceanography 60: 29-45. https://doi.org/10.1016/j.pocean.2004.02.001

Casanova J.-P. \& De Jong L. 2005. A new North-East Atlantic species of Bacescomysis (Mysidacea, Crustacea) with original moth-like antennules. Journal of natural History 39 (21): 1839-1849. https://doi.org/10.1080/00222930400023784

Chevaldonné P., Rastorgueff P.-A., Arslan D. \& Lejeusne C. 2015. Molecular and distribution data on the poorly known, elusive, cave mysid Harmelinella mariannae (Crustacea: Mysida). Marine Ecology 36: 305-317. https://doi.org/10.1111/maec.12139

Clarke W.D. 1962. The genus Gnathophausia (Mysidacea, Crustacea), its Systematics and Distribution in the Pacific Ocean. PhD Thesis, University of California, Berkeley.

Colosi G. 1929. I Misidacei del Golfo di Napoli. Pubblicazioni della Stazione Zoologica di Napoli 9 (3): 405-439.

Czerniavsky V. 1882. Monographia Mysidarum inprimis Imperii Rossici (marin., lacustr. et fluviatilium). Fasc. 1. Trudy Sankt-Peterburgskago obshchestva estestvoispytatelei 12 (2): 1-170.

De Jong-Moreau L. \& Casanova J.-P. 2001. The foreguts of the primitive families of the Mysida (Crustacea, Peracarida): a transitional link between those of the Lophogastrida (Crustacea, Mysidacea) and the most evolved Mysida. Acta Zoologica (Stockholm) 82 (2): 137-147.

https://doi.org/10.1046/j.1463-6395.2001.00077.x

De Jong-Moreau L., Casanova B. \& Casanova J.-P. 2001. Detailed comparative morphology of the perioral structures of the Mysidacea and Euphausiacea (Crustacea): an indication for the food preference. Journal of the Marine Biological Association of the United Kingdom 81 (2): 235-241. https://doi.org/10.1017/S0025315401003691

Deutsche Tiefsee-Expedition 1899. Stationen der Deutschen Tiefsee-Expedition 1898-99. August Hoffmann, Leipzig-Reudnitz.

Fage L. 1941. Mysidacea Lophogastrida - I. The Carlsberg Foundation's oceanographical expedition round the world 1928-1930 and previous Dana-expeditions under the leadership of Prof. Johannes Schmidt. Dana Reports vol. 4 (19): 1-52. Andr. Fred. Høst \& Son, Copenhagen.

Fanelli E. 2007. Trophic Relationships in Demersal Communities of Western Mediterranean: Case Studies from Coastal and Deep-Sea Ecosystems. PhD Thesis, Università degli Studi di Viterbo.

Faxon W. 1895. XV. The stalk-eyed Crustacea. In: Reports on an exploration off the west coasts of Mexico, Central and South America, and off the Galapagos Islands, in charge of Alexander Agassiz, by the U.S. Fish Commission Steamer Albatross during 1891. Memoirs of the Museum of Comparative Zoölogy at Harvard College 18: 1-292.

Frutos I. \& Sorbe J.-C. 2008. El Cachucho: un punto caliente de biodiversidad marina en el mar Cantâbrico. In: SIEBM - XV Simpósio Ibérico de Estudos de Biologia Marinha. Funchal, Madeira, 9 a 13 de Setembro de 2008: 48.

Frutos I. \& Sorbe J.-C. 2013. Bathyal suprabenthic assemblages from the southern margin of the Capbreton Canyon ("Kostarrenkala" area), SE Bay of Biscay. Deep-Sea Research Part II: Topical Studies in Oceanography 102: 291-309. https://doi.org/10.1016/j.dsr2.2013.09.010 
Fukuoka K. 2009. Deep-sea mysidaceans (Crustacea: Lophogastrida and Mysida) from the northwestern North Pacific off Japan, with descriptions of six new species. In: Fujita T. (ed.) Deep-sea fauna and pollutants off Pacific coast of northern Japan. National Museum of Nature and Science Monographs 39: 405-446.

Gordon J.D.M. \& Duncan J.A.R. 1987. Deep-sea bottom-living fishes at two repeat stations at 2200 and $2900 \mathrm{~m}$ in the Rockall Trough, northeastern Atlantic Ocean. Marine Biology 96 (3): 309-325.

https://doi.org/10.1007/BF00412512

Hansen H.J. 1908. Crustacea Malacostraca. The Danish Ingolf Expedition 3 (2), Bianco Luno, Copenhagen.

Hansen H.J. 1910. The Schizopoda of the Siboga Expedition. Siboga Expeditie, Monographie 37, E.J. Brill, Leyden.

Hansen H.J. 1927. Les Schizopodes. Expéditions scientifiques du "Travailleur" et du "Talisman" pendant les années 1880, 1881, 1882, 1883, G. Mason, Paris.

Hargreaves P.M. 1997. The near-bottom distribution of the genus Boreomysis (Crustacea: Mysidacea) in the Porcupine Seabight, Northeastern Atlantic. Arquipélago. Life and Marine Sciences 15A: 51-64.

Hendrickx M.E. 2019. Species of Gnathophausiidae (Crustacea, Lophogastrida) collected off the west coast of Baja California, Mexico, during the TALUD cruises. Zootaxa 4609 (3): 449-468.

https://doi.org/10.11646/zootaxa.4609.3.3

Hendrickx M.E. \& Hernández-Payán J.C. 2018. Redescription of the mysid Petalophthalmus armiger Willemoes-Suhm, 1875 (Crustacea: Mysida: Petalophthalmidae) and distribution off western Mexico. Zootaxa 4444 (3): 283-298. https://doi.org/10.11646/zootaxa.4444.3.4

Holt E.W.L. \& Tattersall W.M. 1905. Schizopodous Crustacea from the north-east Atlantic slope. In: Report on the Sea and Inland Fisheries of Ireland for 1902 and 1903. Scientific Investigations. Fisheries Branch. Department of Agriculture for Ireland. Dublin. Annual Report 1902-1903, Pt. II, App. IV: 99-152.

Holt E.W.L. \& Tattersall W.M. 1906. Schizopodous Crustacea from the Northeast Atlantic Slope. Supplement. Report on the Sea and Inland Fisheries of Ireland. Part II. Scientific Investigations Appendix V (1904): 1-49.

ICZN (International Commission on Zoological Nomenclature) 1999. International Code of Zoological Nomenclature, $4^{\text {th }}$ Ed. International Trust for Zoological Nomenclature, London.

Ii N. 1964. Mysidae (Crustacea). Fauna Japonica 7, Biogeographical Society of Japan, Tokyo.

Illig G. 1906. 2. Bericht über die neuen Schizopodengattungen und -arten der Deutschen TiefseeExpedition 1898-1899. I. Mysideen. Zoologischer Anzeiger 30: 194-211.

Illig G. 1930. Die Schizopoden der Deutschen Tiefsee-Expedition. In: Chun C. (ed.) Wissenschaftliche Ergebnisse der Deutschen Tiefsee-Expedition auf dem Dampfer "Valdivia" 1898-1899. Vol. 22: 397620. Gustav Fischer Verlag, Jena.

Kathman R.D., Austin W.C., Saltman J.C. \& Fulton J.D. 1986. Identification Manual of the Mysidacea and Euphausiacea of the Northeast Pacific. Canadian Special Publication of Fisheries and Aquatic Sciences 93, Department of Fisheries and Oceans, Ottawa.

Kobusch W. 1998. The foregut of the Mysida (Crustacea, Peracarida) and its phylogenetic relevance. Philosophical Transactions of the Royal Society. B. Biological Sciences 353: 559-581.

https://doi.org/10.1098/rstb.1998.0227 
Kröncke I. \& Türkay M. 2003. Structural and functional aspects of the benthic communities in the deep Angola Basin. Marine Ecology Progress Series 260: 43-53. https://doi.org/10.3354/meps260043

Lagardère J.-P. 1972. Recherches sur l'alimentation des crevettes de la pente continentale marocaine. Téthys 3 (3): 655-675.

Lagardère J.-P. 1983. Les mysidacés de la plaine abyssale du Golfe de Gascogne 1. Familles des Lophogastridae, Eucopiidae et Petalophthalmidae. Bulletin du Muséum national d'histoire naturelle, $4^{\text {ème }}$ série, section A (Zoologie, Biologie, Écologie animale) 5 (3): 809-843.

Madurell T. \& Cartes J.E. 2003. The suprabenthic peracarid fauna collected at bathyal dephts in the Ionian Sea(eastern Mediterranean).Crustaceana 76(5):611-624.https://doi.org/10.1163/156854003322316245

Mauchline J. 1980. The biology of mysids and euphausiids. In: Blaxter J.H.S., Russell F.S. \& Young M. (eds) Advances in Marine Biology. Vol. 18, Academic Press, London.

Mauchline J. 1986. The biology of the deep-sea species of Mysidacea (Crustacea) of the Rockall Trough. Journal of the Marine Biological Association of the United Kingdom 66 (4): 803-825.

https://doi.org/10.1017/S002531540004844X

Mauchline J. \& Murano M. 1977. World list of the Mysidacea, Crustacea. Journal of the Tokyo University of Fisheries 64: 39-88.

Mees J. \& Meland K. (eds) 2019. World List of Lophogastrida, Stygiomysida and Mysida. Available from http://www.marinespecies.org/mysidacea/ [accessed 30 Aug. 2019].

Meland K. \& Aas P.Ø. 2013. A taxonomical review of the Gnathophausia (Crustacea, Lophogastrida), with new records from the northern mid-Atlantic ridge. Zootaxa 3664 (2): 199-225.

https://doi.org/10.11646/zootaxa.3664.2.5

Meland K. \& Brattegard T. 1995. Redescription of the North Atlantic Pseudomma species (Crustacea, Mysidacea), with the addition of Pseudomma jasi n.sp. Sarsia 80 (2): 107-144.

https://doi.org/10.1080/00364827.1995.10413585

Meland K. \& Willassen E. 2007. The disunity of "Mysidacea" (Crustacea). Molecular Phylogenetics and Evolution 44 (3): 1083-1104. https://doi.org/10.1016/j.ympev.2007.02.009

Meland K., Mees J., Porter M. \& Wittmann K.J. 2015. Taxonomic review of the orders Mysida and Stygiomysida (Crustacea, Peracarida). PLoS ONE 10 (4): e0124656.

https://doi.org/10.1371/journal.pone.0124656

Milne Edwards H. 1837. Histoire naturelle des Crustacés, comprenant l'anatomie, la physiologie et la classification de ces animaux. Vol. 2. Librairie Encyclopédique de Roret, Paris.

https://doi.org/10.5962/bhl.title.16170

Miyashita L.K. \& Calliari D. 2014. Revision of mysids (Crustacea: Peracarida: Mysida) zoogeographical distribution in the south-west Atlantic $\left(0^{\circ}\right.$ to $\left.40^{\circ} \mathrm{S}\right)$. Marine Biodiversity Records 7 (E5): 1-13.

https://doi.org/10.1017/S1755267213001176

Murano M. 1971. Mysidacean fauna in Sagami Bay and Suruga Bay. Proceedings of the Japanese Society of Systematic Zoology 7: 45-48. https://doi.org/10.19004/pjssz.7.0_45

Murano M. 1974. Mysidacea from the Central and Western Pacific I. The genus Pseudomma (tribe Erythropini). Publications of the Seto marine biological Laboratory 21 (5/6): 287-334.

https://doi.org/10.5134/175878

Murano M. \& Fukuoka K. 2008. A systematic study of the genus Siriella (Crustacea: Mysida) from the Pacific and Indian Oceans, with descriptions of fifteen new species. National Museum of Nature and Science Monographs 36: 1-173. 
Murano M. \& Krygier E.E. 1985. Bathypelagic mysids from the northeastern Pacific. Journal of Crustacean Biology 5 (4): 686-706. https://doi.org/10.2307/1548246

Nouvel H. 1942. Diagnoses préliminaires de Mysidacés nouveaux provenant des campagnes du Prince Albert 1er de Monaco. Bulletin de l'Institut Océanographique de Monaco 831: 1-12.

Nouvel H. \& Lagardère J.-P. 1976. Les Mysidacés du talus continental du Golfe de Gascogne. I. Tribu des Erythropini (genre Erythrops excepté). Bulletin du Muséum national d'Histoire naturelle, $3^{\text {ème }}$ sér. no. 414, Zoologie 291: 1243-1324.

Nouvel H., Casanova J.-P. \& Lagardère J.-P. 1999. 4. Ordre des Mysidacés (Mysidacea Boas 1883). In: Forest J. (ed.) Traité de Zoologie. Tome VII. Crustacés. Fasc. IIIA. Crustacés Péracarides. Mémoires de l'Institut Océanographique, Monaco 19: 39-86.

Ohlin A. 1901. Arctic Crustacea collected during the Swedish Arctic expeditions 1898, 1899 and 1900 under the direction of A.G. Nathorst and G. Kolthoff. II. Decapoda, Schizopoda. Kongliga Svenska Vetenskaps-Akademiens Handlingar, Bihang 27 (4): 1-91.

Ortiz M., Winfield I. \& Cházaro-Olvera S. 2012. Lista actualizada y clave ilustrada para los géneros de misidáceos (Crustacea, Peracarida) del Mar Intra-Americano. Revista Mexicana de Biodiversidad 83: 983-1003. https://doi.org/10.22201/ib.20078706e.2012.4.1279

Panampunnayil S.U. 1982. Description of a new species of Petalophthalmus (Mysidacea) with a revised definition of the genus. Journal of Plankton Research 4 (3): 643-650.

Perrier E. 1893. Schizopoda. In: Perrier E. (ed.) Traité de Zoologie. Arthropodes. Vol. 3: 1025-1027. G. Masson, Paris.

Petryashov V.V. 1993. Mysids (Crustacea, Mysidacea) of upper bathyal zone of the Kurile Islands. In: Sirenko B.I. \& Vassilenko S.V. (eds) The fauna of the continental slope of the Kurile Islands based on collections of 33 voyage r/v “Odyssey". Explorations of the Fauna of the Seas 46 (54): 77-106.

Petryashov V.V. 2005a. Biogeographical division of the North Pacific sublittoral and upper bathyal zones by the fauna of Mysidacea and Anomura (Crustacea). Russian Journal of Marine Biology 31 (Suppl. 1): S9-S26.

Petryashov V.V. 2005b. Mysids (Crustacea, Mysidacea) collected by Soviet and Russian Antarctic expeditions. Lophogastrida, Petalophthalmida, and Mysida: Boreomysidae. Zoologicheskij Zhurnal 84 (8): 957-973.

Petryashov V.V. 2009. Order Mysidacea. In: Vassilenko S.V. \& Petryashov V.V. (eds) Rotifera, Pycnogonida, Cirripedia, Leptostraca, Mysidacea, Hyperiidea, Caprellidea, Euphausiacea, Dendrobranchiata, Pleocyemata, Anomura, and Brachyura. In: Sirenko B.I. (ser. ed.) Illustrated Keys to Free-Living Invertebrates of Eurasian Arctic Seas and Adjacent Deep Waters. Vol. 1: 65-83. Alaska Sea Grant Publications, Fairbanks, USA.

Petryashov V.V. 2014. Deep-sea fauna of European seas: An annotated species check-list of benthic invertebrates living deeper than $2000 \mathrm{~m}$ in the seas bordering Europe. Mysida, Lophogastrida. Invertebrate Zoology 11 (1): 183-191.

Pillai N.K. 1965. A review of the work of shallow-water Mysidacea of the Indian waters. In: Proceedings of the Symposium on Crustacea, held at Ernakulam from January 12 to 15, 1965. Part V: 1681-1728. Marine Biological Association of India, Mandapam Camp.

Pillai N.K. 1968. Redescription of Petalophthalmus oculatus (Crustacea: Mysidacea) based on an adult female collected from near the type locality. Journal of Zoology 155: 283-291.

https://doi.org/10.1111/j.1469-7998.1968.tb03053.x 
Price W.W. \& Heard R.W. 2009. 53. Mysida (Crustacea) of the Gulf of Mexico. In: Felder D.L. \& Camp D.K. (eds) Gulf of Mexico - Origins, Waters, and Biota. Vol. 1: Biodiversity: 929-938. Texas A\&M Press, Texas.

Price W.W., McAllister A.P., Towsley R.M. \& DelRe M. 1986. Mysidacea from continental shelf waters of the northwestern Gulf of Mexico. Contributions in Marine Science 29: 45-58.

Price W.W., Heard R.W., Aas P. \& Meland K. 2009. 52. Lophogastrida (Crustacea) of the Gulf of Mexico. In: Felder D.L. \& Camp D.K. (eds) Gulf of Mexico - Origins, Waters, and Biota. Vol. 1: Biodiversity: 923-927. Texas A\&M Press, Texas.

San Vicente C. 2010. Mysidaceans. In: Coll M., Piroddi C., Steenbeek J., Kaschner K., Ben Rais Lasram F., Aguzzi J., Ballesteros E., Bianchi C.N. et al. (eds) The biodiversity of the Mediterranean Sea: estimates, patterns, and threats. PLOS ONE 5 (8): e11842: 254-275. https://doi.org/10.1371/journal.pone.0011842

San Vicente C. 2011. Chapter 1. Species diversity of antarctic mysids (Crustacea: Lophogastrida and Mysida). In: Mulder T.J. (ed.) Antarctica: Global, Environmental and Economic Issues: 1-80. Nova Science Publishers, Inc.

San Vicente C. 2016. An annotated check-list of lophogastrids (Crustacea: Lophogastrida) from the seas of the Iberian Peninsula. Zootaxa 4178 (4): 481-502. https://doi.org/10.11646/zootaxa.4178.4.2

San Vicente C. 2017. Geographical and bathymetric distribution of mysids (Crustacea: Mysida) in the seas of the Iberian Peninsula. Zootaxa 4244: 151-194. https://doi.org/10.11646/zootaxa.4244.2

San Vicente C. \& Corbari L. 2015. A new bathyal mysid of the family Petalophthalmidae (Crustacea: Mysida) from the Bismarck Sea (Western Tropical Pacific Ocean). Zootaxa 3925 (2): 241-256. https://doi.org/10.11646/zootaxa.3925.2.6

San Vicente C. \& Sorbe J.-C. 2008. Hansenomysis anaramosae n. sp., a new suprabenthic mysid (Crustacea: Mysidacea: Petalophthalmidae) from the Bellingshausen Sea (Southern Ocean). Organisms, Diversity \& Evolution 8: 21.e1-21.e9. https://doi.org/10.1016/j.ode.2006.08.005

San Vicente C., Frutos I. \& Sorbe J.-C. 2012. Mysidopsis cachuchoensis sp. nov. (Crustacea: Mysida: Mysidae), a new suprabenthic mysid from bathyal soft-bottoms of the Le Danois Bank (southern Bay of Biscay). Journal of the Marine Biological Association of the United Kingdom 93 (03): 769-780. https://doi.org/10.1017/S0025315412000987

San Vicente C., Frutos I. \& Cartes J.E. 2014. Petalophthalmus papilloculatus sp. nov. (Crustacea: Mysida: Petalophthalmidae), a new bathyal suprabenthic mysid from the Galicia Bank (NE Atlantic Ocean). Zootaxa 3765 (1): 77-91. https://doi.org/10.11646/zootaxa.3765.1.5

Sawamoto S. 2014. Current status of mysid taxonomy in Southeast Asia. In: Proceedings of LIPI-JSPS Joint Seminar on Coastal Ecosystems in Southeast Asia, 2012. Marine Research in Indonesia 39: 1-14. https://doi.org/10.14203/mri.v39i1.80

Sorbe J.-C. \& Elizalde M. 2013. Temporal changes in the structure of a slope suprabenthic community from the Bay of Biscay (NEAtlantic Ocean). Deep-Sea Research Part II: Topical Studies in Oceanography 106: 179-191. https://doi.org/10.1016/j.dsr2.2013.09.041

Springer S. \& Bullis H.R. Jr. 1956. Collections by the Oregon in the Gulf of Mexico. List of crustaceans, molluscs and fishes identified from the collections made by the exploratory fishing vessel Oregon in the Gulf of Mexico and adjacent seas 1950 through 1955. Special Scientific Report: Fisheries 196: 1-134.

Stuck K.C., Perry H.M. \& Heard R.W. 1979. Records and range extensions of Mysidacea from coastal and shelf waters of the eastern Gulf of Mexico. Gulf Research Reports 6 (3): 239-248.

https://doi.org/10.18785/grr.0603.04 
Tattersall O.S. 1955. Mysidacea. Discovery Reports 28, Cambridge University Press.

Tattersall O.S. 1962. Report on a collection of Mysidacea from South African off-shore and coastal waters (1957-59) and from Zanzibar (1961). Proceedings of the Zoological Society of London 139 (2): 221-247. https://doi.org/10.1111/j.1469-7998.1962.tb01828.x

Tattersall O.S. 1968. A new species of Petalophthalmus (Mysidacea) based on specimens from off Puerto Rico, hitherto referred to Petalophthalmus oculatus. Journal of Zoology 155: 271-282. https://doi.org/10.1111/j.1469-7998.1968.tb03052.x

Tattersall W.M. 1909. The Schizopoda collected by the Maia and Puritan in the Mediterranean. Mittheilungen aus der Zoologischen Station zu Neapel 19 (2): 117-143, Pl. 7.

Tattersall W.M. 1911. Schizopodous Crustacea from the northeast Atlantic slope. Scientific Investigations of the Fisheries Research Board of Ireland (1910), Suppl. II: 1-77.

Tattersall W.M. 1923. Crustacea. Part. VII. - Mysidacea. In: British Antarctic (Terra Nova) Expedition, 1910. Natural History Report. British Museum (Natural History), Zoology 3 (10): 273-304.

Tattersall W.M. 1951. A review of the Mysidacea of the United States National Museum. Bulletin of the United States National Museum 201: 1-292. https://doi.org/10.5962/bhl.part.16843

Tattersall W.M. \& Tattersall O.S. 1951. The British Mysidacea. Vol. 136. Ray Society, Monograph. The Ray Society, London.

Tchindonova, Yu.G. 1981. New data on the systematic position of some deep-sea mysids (Mysidacea, Crustacea) and their distribution in the World Ocean. In: Proceedings of the XIV Pacific Science congress (Khabarovsk, August 1979). Section Marine Biology. Biology of the Pacific Ocean depths. Vol. 1: 24 33. The Academy of the Sciences of the USSR, Far East Science Center, Institute of marine Biology, Vladivostok.

Tchindonova Yu.G. 1993. The distribution of the deep-sea near bottom pelagical Mysidacea (Crustacea) in the World Ocean and the relationship between high taxone in this group of animals. In: Vinogradova N.G. (ed.) The deep-sea bottom fauna in the southern part of the Atlantic Ocean. Transactions of the P.P. Shirshov Institute of Oceanology 127: 147-158.

Türkay M., Allspach A., Bohn J., Cristobo F.J., Fiege D., Kröncke I., Rosenboom W., Ruthensteiner B., Saiz-Salinas J.I. \& Urgorri V. 2006. 1. 4. 7 Mega-Epifauna. In: Balzer W., Alheit J., Emeis K.C., Lass H.U. \& Türkay M. (eds) South-East Atlantic 2000, Leg M48/1; Cruise No. 48, 6 July 2000 - 3 November 2000, Walvis Bay - Walvis Bay. Meteor-Berichte 06-5: 1-27 to 1-32. https://doi.org/10.2312/cr_m48

Vanhöffen E. 1897. 1. Teil. Die Fauna und Flora Grönlands. In: von Drygalski E. (ed.) Grönland Expedition der Gesellschaft für Erdkunde zu Berlin, 1891-1893. Vol. 2, W.H. Kühl, Berlin.

Vanquickelberghe V. 2004. Spatial Distribution and Biodiversity Patterns of the Hyperbenthos along NE Atlantic Continental Margins. Sc.D. thesis, Unversiteit Gent.

Vereshchaka A.L. 1990. Mysids from seamounts of Nazca and Sala-y-Gomez Ridges. Trudy Instituta Okeanologii Akademija Nauk SSSR 124: 118-128.

Vereshchaka A.L. 1995. Makroplankton in the near-bottom layer of continental slopes and seamounts. Deep-Sea Research Part I: Oceanographic Research Papers 42 (9): 1639-1668.

https://doi.org/10.1016/0967-0637(95)00065-E

Wang S. 1998. On new and rare species of Mysidacea (Crustacea) from the northern South China Sea. Studia Marina Sinica 40: 199-244.

Willemoës-Suhm R. von 1873. Notes from the Challenger, VII. Nature 8: 400-403.

https://doi.org/10.1038/008400a0 
Willemoës-Suhm R. von 1874. Von der Challenger-Expedition: Briefe an C.Th. E. v. Siebold, II. Zeitschrift für wissenschaftliche Zoologie 24: ix-xxiii.

Willemoës-Suhm R. von 1875. On some Atlantic Crustacea from the 'Challenger' expedition. Transactions of the Linnean Society of London, $2^{\text {nd }}$ Series Zoology 1 (1): 23-59.

https://doi.org/10.1111/j.1096-3642.1875.tb00433.x

Wittmann K.J. 2008. Two new species of Heteromysini (Mysida, Mysidae) from the Island of Madeira (N.E. Atlantic), with notes on sea anemone and hermit crab commensalisms in the genus Heteromysis S.I. Smith, 1873. Crustaceana 81: 351-374. https://doi.org/10.1163/156854008783564037

Wittmann K.J. (in press). Addenda to the Lophogastrida and Mysida of the "Valdivia" Expedition 18981899, with description of a new species of Longithorax Illig, 1906, and range extension in Echinomysis chuni Illig, 1905 (Crustacea: Malacostraca). Spixiana. Zeitschrift für Zoologie 43.

Wittmann K.J. \& Griffiths C.L. 2018. A new species of Mysidopsis G.O. Sars, 1864 from the Atlantic coast of South Africa, with supplementary descriptions of two additional species and notes on colour and feeding apparatus (Mysida: Mysidae). Journal of Crustacean Biology 38 (2): 215-234.

https://doi.org/10.1093/jcbiol/rux118

Wittmann K.J., Schlacher T.A. \& Ariani A.P. 1993. Structure of recent and fossil mysid statoliths (Crustacea, Mysidacea). Journal of Morphology 215: 31-49. https://doi.org/10.1002/jmor.1052150103

Wittmann K.J., Hernández F., Dürr J., Tejera E., González J.A. \& Jiménez S. 2004. The epi- to bathypelagic Mysidacea (Peracarida) off the Selvagens, Canary, and Cape Verde Islands (NE Atlantic), with first description of the male of Longithorax alicei H. Nouvel, 1942. Crustaceana 76: 1257-1280. https://doi.org/10.1163/156854003773123483

Wittmann K.J., Ariani A.P. \& Lagardère J.-P. 2014. Orders Lophogastrida Boas, 1883, Stygiomysida Tchindonova, 1981, and Mysida Boas, 1883 (also known collectively as Mysidacea). In: Vaupel Klein J.C. von, Charmantier-Daures M. \& Schram F.R. (eds) Treatise on Zoology - Anatomy, Taxonomy, Biology. The Crustacea. Revised and updated, as well as extended from the Traité de Zoologie. Vol. 4B: 189-396. Koninklijke Brill, Leiden. https://doi.org/10.1163/9789004264939_006

Manuscript received: 23 January 2020

Manuscript accepted: 9 March 2020

Published on: 16 April 2020

Topic editor: Rudy Jocqué

Desk editor: Pepe Fernández

Printed versions of all papers are also deposited in the libraries of the institutes that are members of the EJT consortium: Muséum national d'histoire naturelle, Paris, France; Meise Botanic Garden, Belgium; Royal Museum for Central Africa, Tervuren, Belgium; Royal Belgian Institute of Natural Sciences, Brussels, Belgium; Natural History Museum of Denmark, Copenhagen, Denmark; Naturalis Biodiversity Center, Leiden, the Netherlands; Museo Nacional de Ciencias Naturales-CSIC, Madrid, Spain; Real Jardín Botánico de Madrid CSIC, Spain; Zoological Research Museum Alexander Koenig, Bonn, Germany; National Museum, Prague, Czech Republic. 